\title{
Rapid Mapping and Deformation Analysis over Cultural Heritage and Rural Sites Based on Persistent Scatterer Interferometry
}

\author{
D. Tapete $^{1}$ and F. Cigna ${ }^{2}$ \\ ${ }^{1}$ Department of Earth Sciences, University of Florence, Via G. La Pira 4, 50121 Florence, Italy \\ ${ }^{2}$ British Geological Survey, Natural Environment Research Council, Nicker Hill, Keyworth, Nottingham NG12 5GG, UK
}

Correspondence should be addressed to D. Tapete, deodato.tapete@gmail.com

Received 23 May 2012; Accepted 3 July 2012

Academic Editor: Francesco Soldovieri

Copyright ( 2012 D. Tapete and F. Cigna. This is an open access article distributed under the Creative Commons Attribution License, which permits unrestricted use, distribution, and reproduction in any medium, provided the original work is properly cited.

\begin{abstract}
We propose an easy-to-use procedure of "PSI-based rapid mapping and deformation analysis," to effectively exploit Persistent Scatterer Interferometry (PSI) for multispatial/temporal hazard assessment of cultural heritage and rural sites, update the condition report at the scale of entire site and single building, and address the conservation strategies. Advantages and drawbacks of the methodology are critically discussed based on feasibility tests performed over Pitigliano and Bivigliano, respectively, located in Southern and Northern Tuscany, Italy, and representative of hilltop historic towns and countryside settlements chronically affected by natural hazards. We radar-interpreted ERS-1/2 (1992-2000) and ENVISAT (2003-2010) datasets, already processed, respectively with the Permanent Scatterers (PSs) and Persistent Scatterers Pairs (PSPs) techniques, and assigned the levels of conservation criticality for both the sites. The PSI analysis allowed the zoning of the most unstable sectors of Pitigliano and showed a good agreement with the most updated hazard assessment of the cliff. The reconstruction of past/recent deformation patterns over Bivigliano confirmed the criticality for the Church of San Romolo, supporting the hypothesis of a correlation with local landslide phenomena, as also perceived from the annual motions observed over the entire site, where several landslide bodies are mapped.
\end{abstract}

\section{Introduction}

One of the main challenges in conducting a technological transfer process consists in communicating developments and achievements of science to the potential stakeholders, to effectively contribute to the building and strengthening of their capabilities in the use of new technologies for the specific fields of application. This issue is currently particularly relevant in the perspective of spreading and encouraging the use of satellite radar data for deformation analyses, not only in geological and environmental applications but also in the management and conservation of built heritage in cultural and rural sites.

In this regard, in the last decades, the standard approach of Synthetic Aperture Radar Interferometry (InSAR) [1, 2] has increasingly found successful implementation in ground motions monitoring and deformation analyses at multiple scales, mainly relating to natural hazard events [3-6], geological processes $[7,8]$, and human-induced phenomena
$[9,10]$. But a significant improvement, especially for analyses over urbanized areas, infrastructure, and human settlements [11-14], has been achieved with the multi-interferogram approaches referred to as Persistent Scatterer Interferometry (PSI). The latter are actually performed by means of different algorithms (among which those developed by different authors [15-19]), which share the common feature of providing point wise information regarding displacements of reflective targets recognized as Persistent Scatterer (PS) throughout long data stacks of processed SAR images.

Hence, the PSI approaches are nowadays validated techniques which can allow a quantitative estimation of the degree of (in)stability of an entire region, an enclosed sector and even single clusters of buildings/elements on the ground to be performed, with a temporal reconstruction up to 1992 in case of availability of ERS-1/2 satellite imagery. This actually corresponds to the so-called back monitoring, as firstly defined by Cigna et al. [12] and specifically adapted to structural monitoring and early stage warning of cultural 
heritage sites by Tapete et al. [20]. The demonstration that PSI data can support the preventive diagnosis of monuments and historical buildings induces to consider such techniques as potential routine tools to monitor and assess the stability and, more generally, the condition over time, to be used by heritage bodies, superintendences, public administrations in charge of cultural heritage management, conservators, and practitioners.

A further chance for that is currently offered by the increasing number of projects and acquisition programmes at regional, national, and, sometimes, transnational level, which are aimed at the creation of databases containing processed PSI data thought to be finally used by public bodies, local authorities, and a wide spectrum of stakeholders and end-users, in their ordinary activities of land and urban environment planning and management. We can here cite, for instance, the ESA GMES project Terrafirma [21] and the Seventh Framework Programme EU project PanGeo [22], as well as the Extraordinary Plan of Environmental Remote Sensing (EPRS-E), that is, the Italian project established between the Italian Ministry of Environment Territory and Sea (METS), Chairperson of the Council of Ministers Department of Civil Protection and the Ministry of Defense in agreement with the Regions and Autonomous Provinces, to acquire, process, and periodically update PSI data over the whole Italian territory for environmental and civil protection activities [23].

Although such initiatives are frequently designed for other uses than application on cultural heritage sites, it cannot exclude that this typology of PSI data can constitute a precious reservoir of information for the preservation of monuments and historic centres, as also recently suggested by Trigila et al. [24] for landslide risk assessment in cultural heritage sites.

The present work is specifically aimed at proposing a simple and easy-to-use methodology to exploit PSI data for rapid mapping and deformation analysis over hilltop historic centres and rural sites, based on the results of feasibility tests performed on two case studies located in Tuscany, Central Italy. The latter were purposely selected as examples of real-world situations and related analytical issues that potential end-users (e.g., superintendence officers, conservators) might have to tackle, especially if they have to radar-interpret PSI data not necessarily processed to be used for cultural heritage applications or to be focused over a particular area of interest at an appropriate scale of analysis. Under this perspective, ERS-1/2 (1992-2000) and ENVISAT (2003-2010) PSI data, already processed in the framework of the EPRS-E project [23] by means of, respectively, the PSInSAR technique [16] and PSPDIFSAR approach (Persistent Scatterers Pairs-DIFferential InSAR; [15]), were radar-interpreted as they are, without any further processing. The results of these site-specific analyses are here presented to critically discuss the potentials and limits of such PSI-based deformation analysis, in terms of real usefulness for preventive diagnosis of cultural heritage and land management in rural environments.

\section{PSI-Based Procedure of Preventive Diagnosis}

2.1. PSI Techniques. Superficial deformation affecting the area covered by the processed radar imagery (Area Of Interest (AOI)) acquired by means of space-borne SAR sensors can be detected after a PSI processing, since the employed algorithms allow the identification of natural/artificial reflectors on the ground. The latter keep their dielectric properties quite constant over the monitoring period and, consequently, act as permanent reflectors (Persistent Scatterer-(PS)) with respect to the microwave wavelengths generated and sent by the active satellite sensors. For each identified PS, the multiinterferogram processing of long data stacks of SAR images covering the AOI highlights the occurrence of changes in its spatial position along the Line Of Sight (LOS) of the satellite and provides an estimate, over time, of the LOS component of the real displacement vector, which geometrically describes the deformation of the point wise target.

The final output of such PSI processing consists of a distribution, over the AOI, of clusters and/or isolated PS; for each of them the following parameters and information are retrieved:

(i) longitude and latitude coordinates, associated with the height $(h)$ and related standard deviation $\left(\mathrm{SD}_{h}\right)$;

(ii) estimate along the LOS of the yearly deformation rate $\left(V_{\mathrm{LOS}}\right)$, usually expressed in $\mathrm{mm} / \mathrm{yr}$, and related standard deviation ( $\mathrm{SD}_{\mathrm{VLOS}}$ );

(iii) deformation time series, where the single values of LOS displacements (expressed in $\mathrm{mm}$ ) estimated according to the sampling frequency of the satellite are plotted versus the monitoring interval;

(iv) PS coherence, that is, one of the quality parameters, together with the LOS velocity and height deviation standards, usually employed to evaluate the informational content of each PS estimate. Its dimensionless value, ranging between 0 and 1 , gives a measure of how much the single time series fits with the deformation model used for the PSI processing.

Different authors $[25,26]$ have demonstrated that the PS usually corresponds to boulders and outcrops within natural contexts, man-made structures and infrastructure in builtup areas. In this regard, monuments, architectural elements with prominent and multiangular shape (e.g., pillars, towers, spires), archaeological structures (e.g., pinnacles, columns, ruins), and findings scattered on the ground (e.g., column drums, fallen architraves) can generate PS after PSI processing. This evidence has been recently confirmed by the results of different site-specific analyses, such as those discussed elsewhere $[13,20,27,28]$.

The papers $[19,27]$ also provide an extended theoretical discussion of the basic principles of the PSI processing (particularly the PSInSAR technique [16], used for the PSI processing of the radar data here analyzed) with specific reference to cultural heritage contexts, as well as schematic examples of the deterioration processes which can be monitored (e.g., land subsidence, masonry toppling, 
crack opening, collapses). The wide spectrum of detectable phenomena is evidently coupled by intrinsic pros and cons. If on one hand the PSI techniques can be successfully exploited for different typologies of instability processes, on the other hand the retrieved estimates only give information about the superficial effects of deterioration and instability phenomena which might be actually attributed to different triggering causes. Hence, solid background knowledge of the AOI and on-site inspections are frequently the key elements to achieve a correct radar interpretation of the PSI data.

Nevertheless, the last decade of PSI applications on environmental, geological, and urban topics confirms the reliability of these techniques, especially in terms of interoperability with conventional field observations and investigations [29, cum biblio]. This property is evidently essential for the purposes of a rapid mapping based on PSI data, like that proposed in this paper, which starts from an evaluation, carried out remotely, of the conservation issues affecting the built heritage over the AOI, as preparatory action to the execution of targeted and tailored terrestrial surveys.

2.2. PSI-Based Rapid Mapping. With the term "PSI-based rapid mapping" we mean the methodology and related final product to assess the (in)stability conditions over the AOI and reconstruct their past and/or recent evolution, by means of a multispatial and temporal analysis of PSI data which uses the LOS velocity estimates and the associated directions of movement (towards or away from the satellite) as reliable satellite evidences of "conservation criticalities." In particular, the latter term refers to natural and/or human-induced factors, conditions, and dynamics which can bring to the triggering of deterioration processes and more generally to key areas of concern for the conservation of the AOI.

The main objective of a PSI-based rapid mapping is the production of a map (updated as much as possible, dependently on the last SAR image of the processed data stacks) of the deformation patterns recognized after the PSI processing, which are likely to be related to recent, ongoing, or, even, upcoming deterioration phenomena. This map is expected to preventively highlight the unstable sectors of a monument, archaeological site, historic centre, or rural settlement rather than the stable ones ("preventive diagnosis"), thereby becoming a practical guiding tool for the selective zoning of the critical areas, where the execution of surveys and stabilization interventions is found as a priority.

The proposed procedure (Figure 1) is aimed at the extraction of the maximum amount of information in terms of deformation estimates, especially in cases of already existing PSI data, which were not processed with the main purpose of being used for cultural heritage applications. In doing that, the sequence of the different phases constituting the methodology is thought to avoid both under- and overestimation of the identified PS, as well as possible misinterpretation of those PSs which are actually pertinent to unrelated elements on the ground, located close to the objects of interest.

In this regard, the first step is the "background phase." It is specifically dedicated to the collection and review of all the existing information about the AOI and its heritage, to build a background knowledge which should address the subsequent multispatial and temporal analysis of the PSI data.

Before running through the "rapid mapping phase", which is the core of the PSI-based procedure of preventive diagnosis, SAR imagery to process and the deformation model to employ for the PSI processing are to be carefully selected (a specific focus on this issue can be found in [20]). This intermediate step is not tackled in the present paper, since we here consider the case of rapid mapping and deformation analysis carried out on already available and processed multiplatform PSI data. Nevertheless, it is worth mentioning that the choice of the processing parameters can significantly influence the obtained PSI data and, consequently, the reliability of the analysis. Indeed, they might have nonnegligible implications on the actual capability of monitoring deformation at the scale of single building/monument, as well as very localized small-area phenomena, as properly suggested by Colesanti and Wasowski [30].

During the rapid mapping phase, each of the employed PS datasets is progressively analyzed in terms of velocity, spatial distribution, and temporal frame.

The first evaluation concerns the LOS velocity distribution of the PS identified over the AOI. This initial assessment gives a rough idea of the overall stability of the AOI, although it is to be considered only a preliminary impression of the deformation pattern(s) to be confirmed during the subsequent phases. According to the sensitivity of the PSI techniques, the threshold commonly chosen as "interval of relative stability" is fixed at $V_{\mathrm{LOS}}= \pm 1.5 \mathrm{~mm} / \mathrm{yr}$ (where negative values correspond to LOS displacements away from the satellite, while the positive ones towards the satellite).

It means that PSs with value of $-1.5 \mathrm{~mm} / \mathrm{yr} \leq V_{\mathrm{LOS}} \leq$ $+1.5 \mathrm{~mm} / \mathrm{yr}$ are classified as relatively stable, pending the verification that any displacement trend or acceleration/deceleration(s) are recognizable within their respective time series. An area apparently stable might have been affected by deformation in the past. At the opposite, high values of $V_{\mathrm{LOS}}$ can correspond to LOS displacements with acceleration(s) concentrated in temporal intervals limited within the whole monitoring period, which might have consequently influenced the entire PS deformation time series.

Prior to a temporal evaluation of the detected deformation, the PS spatial distribution is analyzed with regard to the location of the site/monuments, to highlight if significant deformation has taken place in correspondence with elements of cultural/civil value, their surroundings, and/or their foundation substratum. In relation to the spatial configuration of the PS clusters, the detected deformation can be distinguished into three main typologies, following the classification proposed in the papers $[20,28]-$ "macropattern," "micropattern," and "localized deformation" (Figure 2).

A macropattern is frequently found over areas affected by natural and/or anthropogenic phenomena active at large scale, in some cases at regional scale. An example is provided 


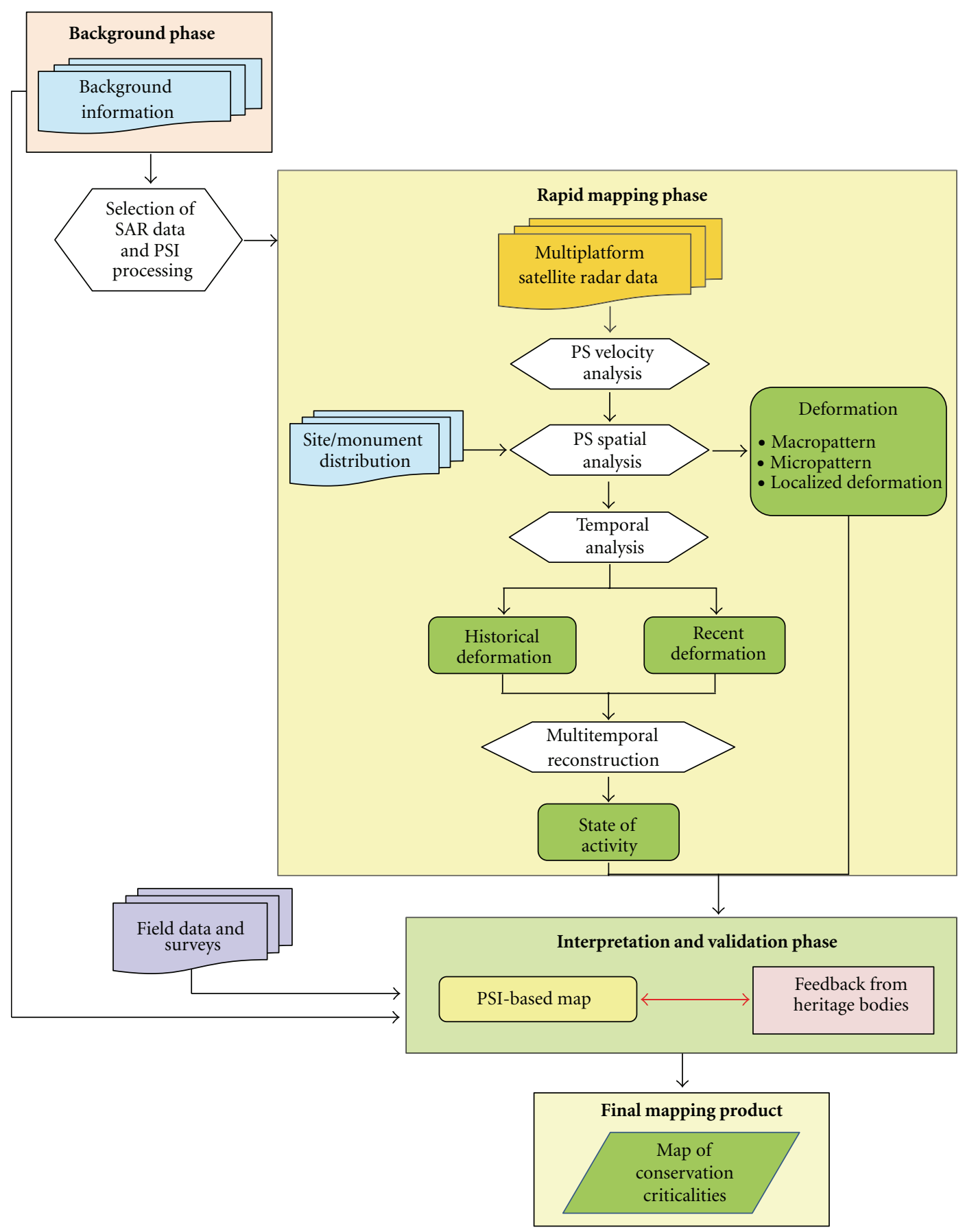

FIGURE 1: Procedure of PSI-based rapid mapping and deformation analysis to retrieve the map of conservation criticalities over cultural heritage and rural sites.

by the subsidence movements observed over recent alluvial deposits of the Tiber river, centre of Rome (Italy), which might have implications for the conservation of urban monuments like the Aurelian Walls (Figure 2(a)). Deformation macropatterns may also affect human settlements, such as in the case of Torrita di Siena, Tuscany (Italy), where a large portion of the town shows LOS displacements away from the satellite (Figure 2(b)). Differently, micropatterns are usually much less extended and typically mark single portions of a site/monument (Figure 2(c), with a zoomed aerial view of Fortezza da Basso, centre of Florence, Italy), likely over buildings located on unstable ground or structural weakness points.

While small clusters of PSs (at least two/three PSs) can identify a micropattern, especially if they show common LOS displacement trends over the same time interval, isolated PS can be referred to localized deformation (Figure 2(c), PS in the yellow circle). The major issue during the interpretation 


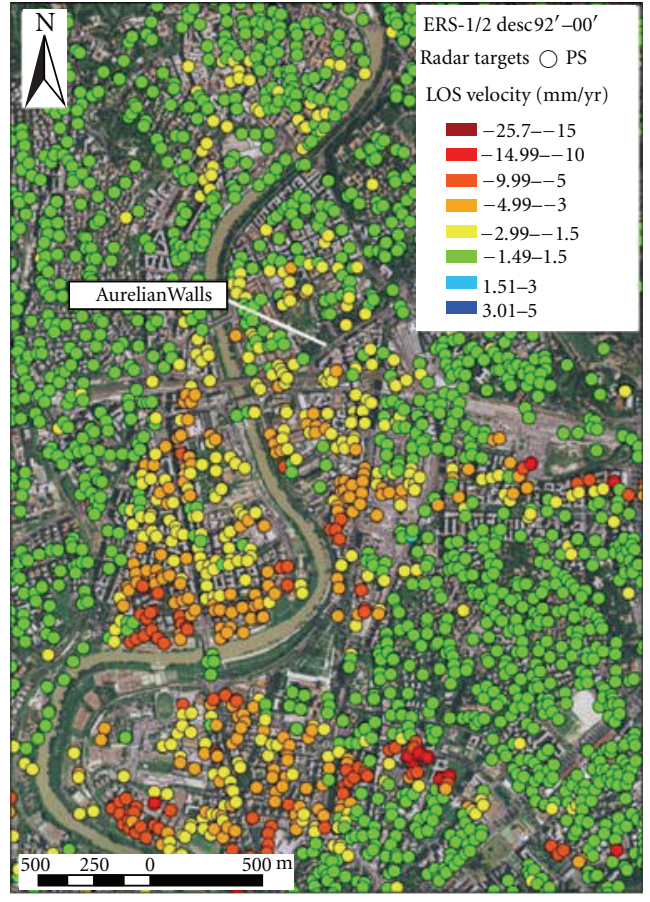

(a)

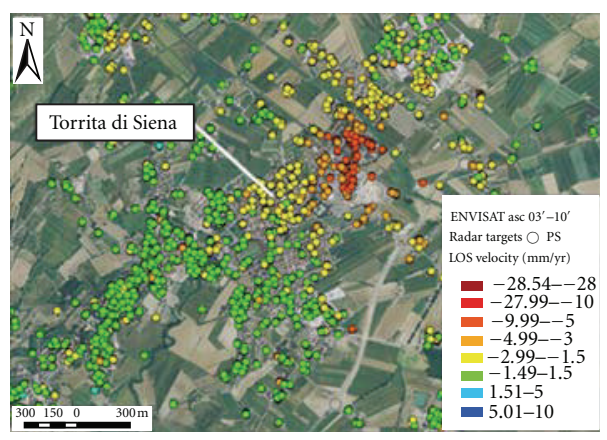

(b)

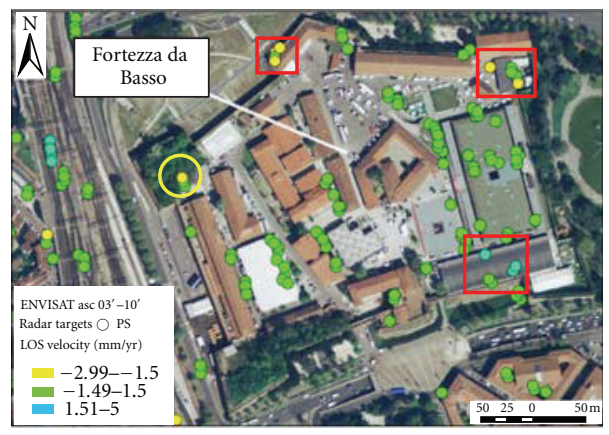

(c)

FIGURE 2: PSI-based deterioration patterns classifiable as macropattern ((a)-(b)); micropattern (i.e., the PS clusters within the red squares in (c)); localized deformation (i.e., the single PS within the yellow circle in (c)).

of such localized deformation concerns the reliability of their informational value. The comparison between their coordinates and height value and the spatial distribution of the built heritage, as well as the knowledge of the local AOI topography, significantly facilitates the attribution of single PS to objects of interest rather than neighbouring unrelated elements (e.g., light poles, infrastructure, public bins). Once the PS has been correctly spatially located, its value in terms of detected deformation is to be carefully assessed in the context of a multitemporal PSI analysis, before classifying it as an occasional displacement event or a negligible deformation estimate.

In this regard, the temporal analysis of multiplatform PS datasets covering distinct and subsequent temporal intervals of observation allows the reconstruction of the evolution of the detected deformation in time, although the different acquisition geometries which characterize the employed satellites still remain a technical constraint to achieve a perfect comparison between multi-platform deformation estimates. Nevertheless, the persistence of deformation over a same area, monument, or architectural element, throughout the different analyzed datasets (i.e., from historical data to recent ones), is generally a reliable indicator of ongoing deterioration processes. Frequently, the analysis of more recent PSI data permits the operators to better and more correctly radar-interpret PS belonging to older datasets, and further confirmation can be retrieved by means of field surveys.

As main outcome of the multitemporal analysis, the state of activity of a deformation is assessed. Regarding the historical data, the absence of any previous PSI-based classification implies that the areas found as subjected to deformation can be classified as follows:

(i) absence of PSI data $\rightarrow$ N.C. (i.e., not classifiable);

(ii) single or clusters of PS with $-1.5 \mathrm{~mm} / \mathrm{yr} \leq V_{\mathrm{LOS}} \leq$ $+1.5 \mathrm{~mm} / \mathrm{yr}$ (independently of the PS spatial distribution) $\rightarrow$ stable;

(iii) single or clusters of PS with $V_{\mathrm{LOS}}$ exceeding the stability threshold, that is, $V_{\mathrm{LOS}} \leq-1.5 \mathrm{~mm} / \mathrm{yr}$ or $V_{\mathrm{LOS}} \geq+1.5 \mathrm{~mm} / \mathrm{yr} \rightarrow$ active.

In the latter case, the definition of the state of activity is coupled with the assessment of the typology of deformation pattern (i.e., macropattern, micropattern or localized deformation).

This type of classification is also employed in those cases where the rapid mapping is performed only based on single-platform PSI data (e.g., PS obtained after multiinterferogram processing of ERS-1/2 radar imagery rather than ENVISAT one). The nonavailability of other platform PS datasets should always be avoided, since it leads to a partial evaluation of the deformational behaviour over the AOI. Nevertheless, it is not rare that, due to economic reasons and/or gaps in the satellite archives, the rapid mapping over the AOI can be carried out with a limited number of PS datasets. Furthermore, even if both the ascending and descending geometries of a same satellite are available, any difference in spatial resolution (e.g., Standard Beam Mode rather than Fine Beam Mode in the case of 


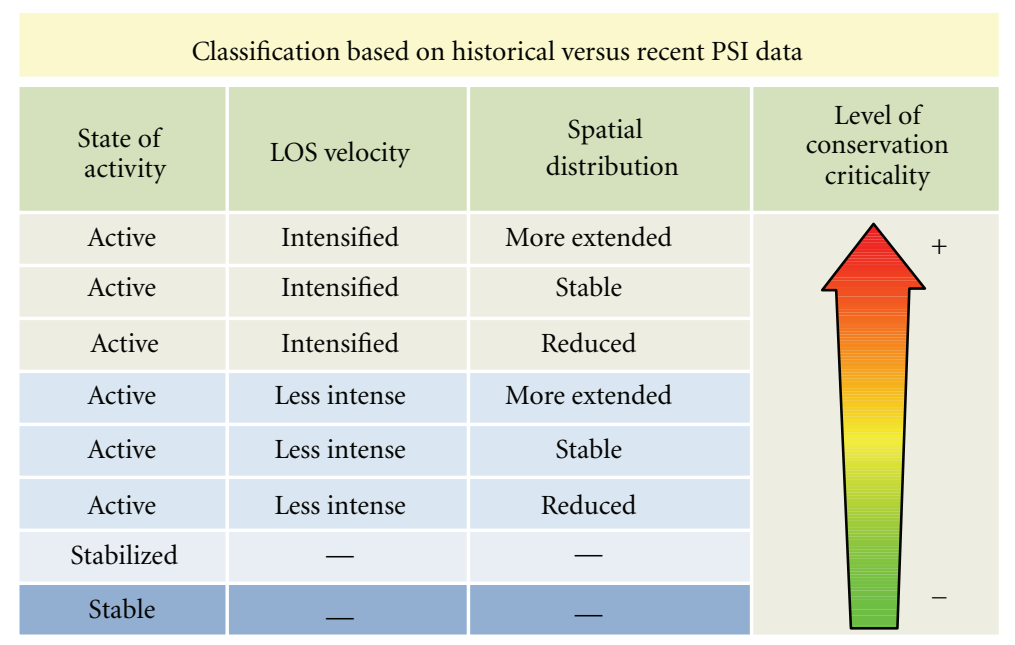

FIGURE 3: Scale of conservation criticality based on multi-temporal analysis of historical and recent PSI data. Increasing level of conservation criticality is associated to deformation, which worsen in terms of state of activity, intensity (LOS velocity- $V_{\text {LOS }}$ ) and/or spatial distribution (i.e., typology of deformation pattern).

RADARSAT-1/2 data stacks) or type of processing can affect the quality of the radar interpretation.

Conversely, when comparing recent PSI data with the historical ones, the following aspects should be taken into account:

(i) if new deformation is detected where no PSs were identified in the previous dataset(s);

(ii) if a previously detected phenomenon is still present and, in such a case, if it is still active or not;

(iii) if the deformation has changed its intensity or not;

(iv) if the new PS spatial distribution still belongs or not to the same class of deformation pattern typology.

According to the previously listed elements, a level of conservation criticality can be assigned, following the scale of progressive alert and priority shown in Figure 3.

The maximum level is attributed to deformation which is found as intensified (i.e., $V_{r} \geq V_{h}$, where $V_{h}$ is the LOS velocity estimated in the historical PSI data and $V_{r}$ in the recent ones) and becomes more spatially extended (e.g., localized deformation changed into micropattern or micropattern changed into macropattern) from the historical data to the recent ones. Similarly, if a new deformation not previously mapped is identified, worse typologies of deformation pattern will be classified with higher alert levels.

On the contrary, if the more updated PSI data record lower yearly deformation rates (i.e., $V_{r} \leq V_{h}$ ), an accurate detailed analysis of the deformation time series is highly suggested, in addition to the mere comparison between the two LOS velocity values. Also, following such a cautionary and conservative approach (similar to that currently employed in PSI-based updating of landslide inventories; [28]), the execution of on-site inspections and feedback from the heritage bodies can provide, during the "interpretation and validation phase," further evidence to classify a sector of the AOI as stabilized (Figure 1).
If no changes occurred over the area, this sector can be classified as stable with a relatively high degree of confidence. Conversely, the absence of PSs over previously moving areas does not necessarily mean that these sectors are now stable. Especially when comparing multiplatform PS datasets, the difference of both the acquisition geometry and temporal period of observation is to be carefully considered. Deformation that was observed and estimated by one satellite at a certain time according to its acquisition geometry might not have been appreciated by another satellite. Lack of PS is evidently an intrinsic weakness of such a type of rapid mapping.

2.3. Map of Conservation Criticalities. The output of the rapid mapping phase is a "PSI-based map" which shows the location, extent, and distribution of the unstable areas of a site and critical sectors of a monument, dependently on the scale and purposes of the analysis. This map is, at the same time, a guide for the execution of targeted on-site checks rather than extensive and expensive surveys and a tool to be validated by the ground truth collected during the inspections themselves.

Indeed, the latter, combined with the background knowledge and the feedback from the heritage bodies (and, more generally, from all the keepers of the cultural and civil elements of interest subjected to deformation during the observation temporal interval) can help to confirm the satellite evidences reported in the PSI-based map. Also, a reliable and strong correlation between the detected deformation and the deterioration phenomena observable on the exposed surfaces can be found, thereby retrieving essential elements to propose a robust interpretation of the analyzed PSI data.

The multilayering analysis of (i) the local natural and/or human-induced factors of deterioration, (ii) the multitemporal deformation estimates detected from satellite, and (iii) the information of the past/recent history of the AOI 


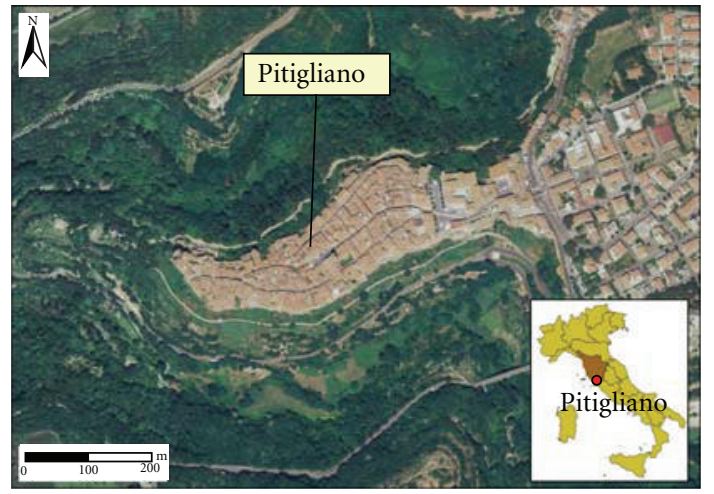

(a)

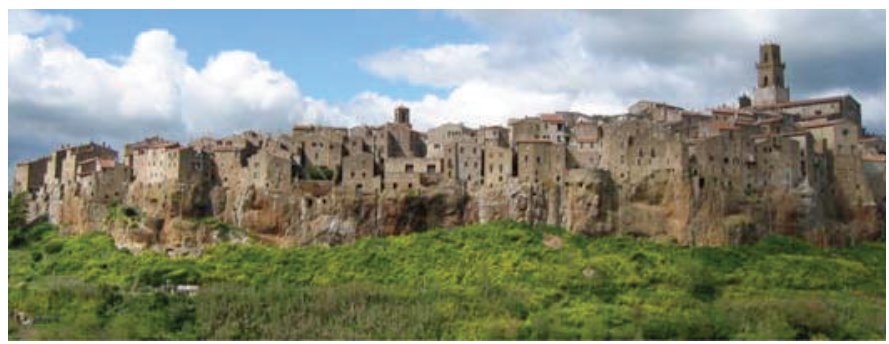

(b)

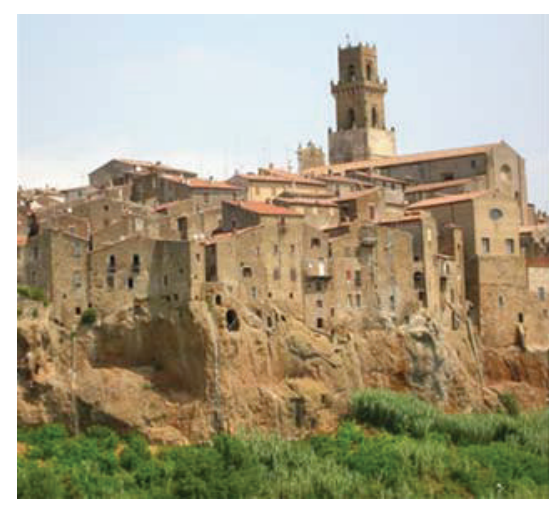

(c)

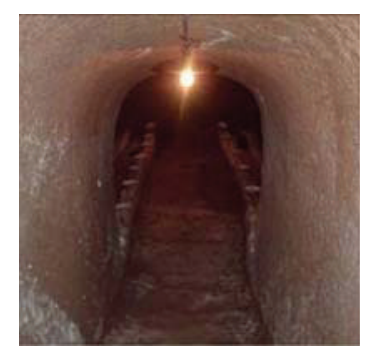

(d)

Figure 4: (a) Aerial view of the Pitigliano cliff, Southern Tuscany and (b) a detail of the southern side. The built heritage along the cliff edge is exposed to rock mass instability mechanisms (c), while an additional hazard can derive from inner collapses of the cavities cut in the tuff substratum underneath the buildings ((d); photo by M. Capretti).

finally translates into a same mapping product, called map of conservation criticalities. This actually represents the final output of the process of rapid mapping and deformation analysis, and it is expected to provide an inventory map in support of the condition reporting of the site/monument of interest. Its degree of updating is evidently strictly dependent on the temporal coverage of the analyzed PSI data. The map of conservation criticalities can be ideally updated, as soon as new satellite acquisitions and more recent PS datasets are added to the previous analysis.

\section{Feasibility Tests}

3.1. Sites Selection, PSI Data, and Rationale. The applicability of the proposed methodology was evaluated by means of feasibility tests carried out on two case studies located in Tuscany, Central Italy, which were purposely selected to be representative of the following typologies of cultural heritage and countryside settlements: (i) hilltop historic towns and (ii) rural sites.

The first category allows the discussion of the conservation issues concerning architectural heritage built at the top of unstable rock masses, whose instability mechanisms can progressively cause structural damages to the monuments located along the edge, even their collapse and consequent disappearance. In these terms, the case of the historic centre of Pitigliano, Southern Tuscany (Figure 4) is a quite demonstrative example of sites where the built heritage potentially at risk is distributed along the entire cliff edge and is exposed to rock mass instability mechanisms, as well as cavities collapse.

For the second category of cultural heritage, the countryside settlement of Bivigliano, north of Florence (Figure 5), was selected, since its cultural, landscape, and built heritage and related conservation issues well exemplify situations of land management quite common over the Italian territory.

These feasibility tests were thought not only to provide a multiple validation of the usefulness of the PSI-based methodology and techniques employed on different contexts of application but also to demonstrate the potential range of stakeholders and end-users who can be interested in the use of PSI data, especially if the latter are made available in the framework of acquisition and processing programmes at local, regional, or national scale.

In this perspective, we exploited the deformation estimates of the previously cited EPRS-E database [23], obtained after PSI processing of C-band data of ENVISAT and ERS-1/2 satellites of the European Space Agency. ENVISAT images, acquired with wavelength $(\lambda)$ of $5.63 \mathrm{~cm}$ and nominal revisiting time of 35 days, were processed with the PSPDIFSAR approach (Persistent Scatterers Pairs-DIFferential InSAR; [15]), while ERS-1/2 images, acquired with $\lambda=$ $5.66 \mathrm{~cm}$ and the same nominal revisiting time as ENVISAT satellite, were processed with the PSInSAR technique [16]. Details about the processing parameters, as well as accuracy and error bars of these PSI estimates, are reported in [31], while the main characteristics of the analyzed PS datasets with specific regard to each test site are summarized in Table 1 . 

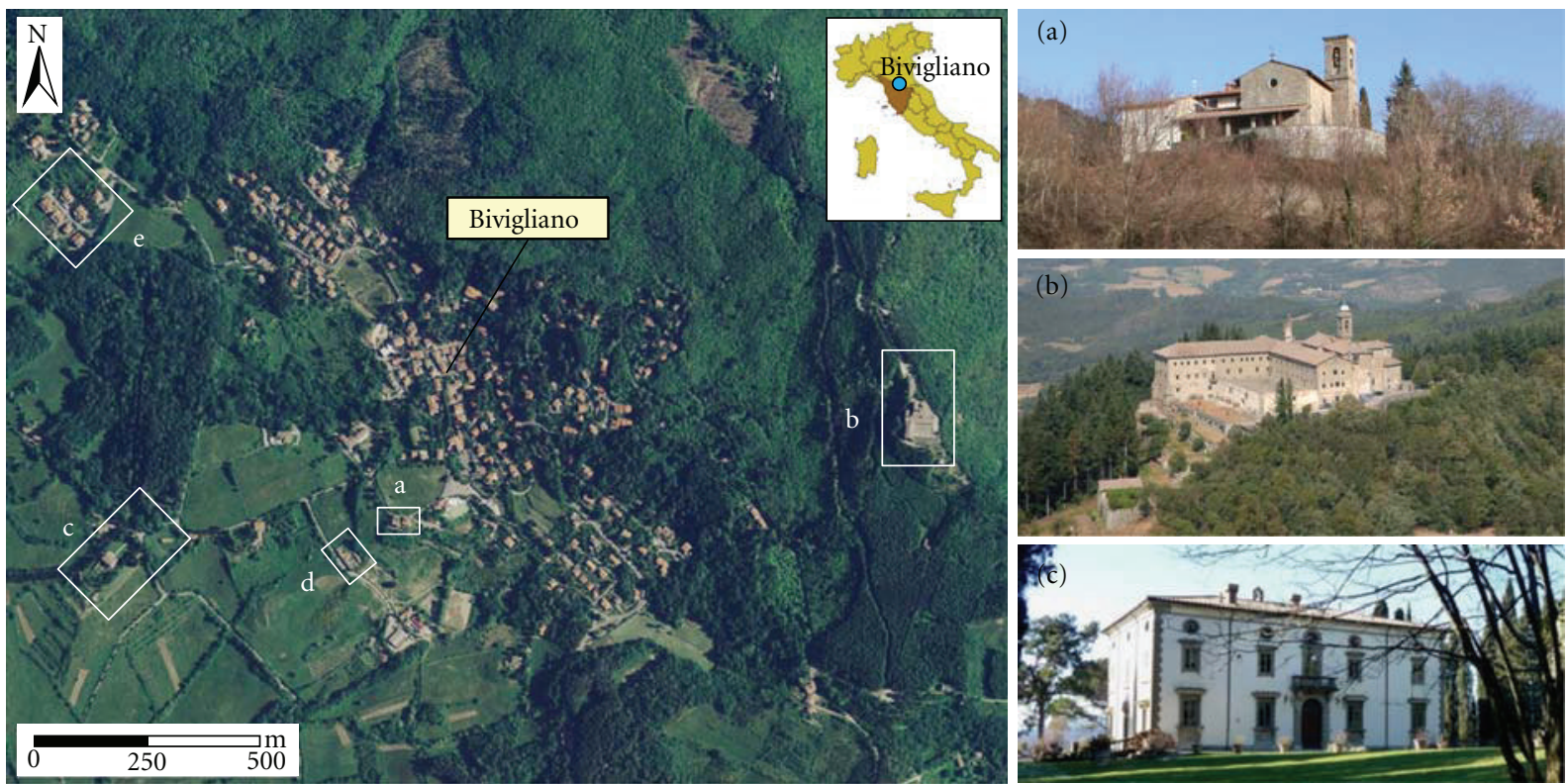

FIGURE 5: Aerial view of the countryside settlement of Bivigliano, Northern Tuscany, with location of the main historic heritage: (a) Church of San Romolo; (b) Convent of Monte Senario; (c) Villa Pozzolini. Further elements of interest for the present feasibility test are (d) the modern cemetery and (e) the area of the local craftsmen (Marroneto).

TABLE 1: Main characteristics of the analyzed datasets; Asc: ascending; Desc: descending. PS density was calculated with regard to the extent of the AOI, which was equal to $0.11 \mathrm{~km}^{2}$ for the Pitigliano cliff and $1.73 \mathrm{~km}^{2}$ for the territory of Bivigliano.

\begin{tabular}{|c|c|c|c|c|c|c|c|c|}
\hline Site & Data stack & Orbit & $\begin{array}{c}\text { Repeat cycle } \\
\text { (days) }\end{array}$ & Time interval & $N$. images & $\begin{array}{l}\text { Processing } \\
\text { technique }\end{array}$ & Total N. PS & $\begin{array}{l}\text { PS density } \\
\left(\mathrm{PS} \mathrm{km}^{-2}\right)\end{array}$ \\
\hline \multirow{3}{*}{ Pitigliano } & ERS-1/2 & Desc & 35 & $\begin{array}{l}10 / 05 / 1992 \\
13 / 12 / 2000\end{array}$ & 60 & PSInSAR & 44 & 400 \\
\hline & ENVISAT & Asc & 35 & $\begin{array}{l}16 / 10 / 2003 \\
27 / 05 / 2010\end{array}$ & 34 & PSP-DIFSAR & 159 & 1446 \\
\hline & ENVISAT & Desc & 35 & $\begin{array}{l}07 / 05 / 2003 \\
09 / 06 / 2010\end{array}$ & 51 & PSP-DIFSAR & 193 & 1775 \\
\hline \multirow{3}{*}{ Bivigliano } & ERS-1/2 & Desc & 35 & $\begin{array}{l}24 / 04 / 1992 \\
27 / 11 / 2000\end{array}$ & 79 & PSInSAR & 145 & 84 \\
\hline & ENVISAT & Asc & 35 & $\begin{array}{l}16 / 10 / 2003 \\
27 / 05 / 2010\end{array}$ & 35 & PSP-DIFSAR & 130 & 75 \\
\hline & ENVISAT & Desc & 35 & $\begin{array}{l}10 / 02 / 2003 \\
28 / 06 / 2010\end{array}$ & 35 & PSP-DIFSAR & 504 & 291 \\
\hline
\end{tabular}

As previously mentioned, these PSI data were radarinterpreted as they are, without any further processing. The rationale behind this technical choice was the possibility to simulate real-world situations that any public administration officer or stakeholder might have to tackle, when exploiting this type of data for applications of rapid mapping and deformation analysis, dealing with both their advantages and shortcomings.

3.2. Hilltop Historic Sites: Pitigliano, Southern Tuscany (Italy). The historic centre of Pitigliano developed through centuries over a flat slab at the top of 25-metre-thick plateau of Pleistocene tuffs, with a present elevation of about $310 \mathrm{~m}$ a.s.l. and approximately oriented along the E$\mathrm{W}$ direction (Figures 4(a)-4(b)). The geological sequence which constitutes the cliff is the result of an intense volcanic activity, mainly related to the volcanic complexes located in the northern Latium [32, 33], and the rock formations originated from the corresponding phases of pyroclastic deposits. Referring to Canuti et al. [34] and Fanti et al. [35] for a detailed geological setting of the Pitigliano cliff, it is here worth mentioning that the welded tuffs belonging to the Sorano/Grotte di Castro Formation represent the substratum underneath the historical buildings. These tuffs were also extensively cut and excavated in depth since Etruscan times, thereby creating a huge network of subterranean caves and corridors, which is actually a sort of "second town" and, at the same time, a source of instability issues due to inner collapses (Figure 4(d)). 


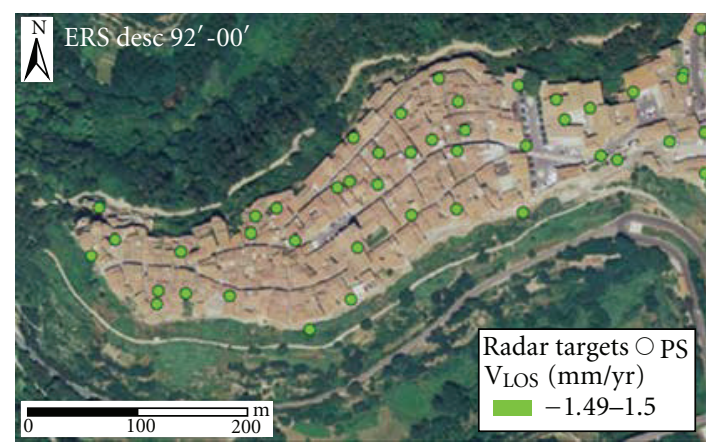

(a)

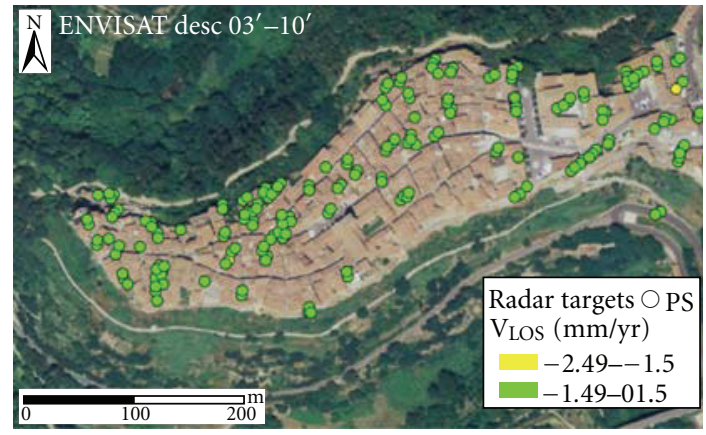

(c)

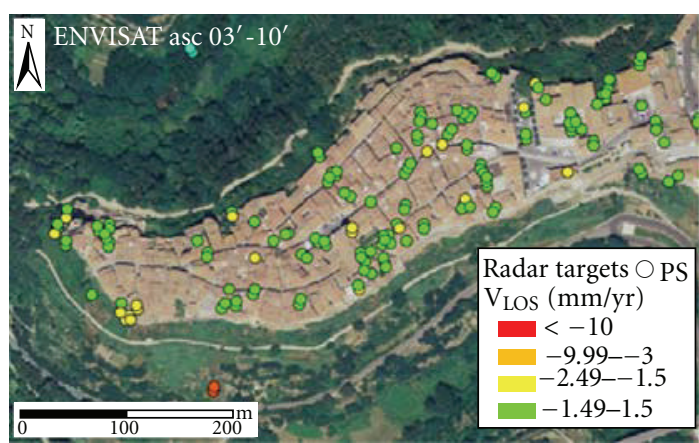

(b)

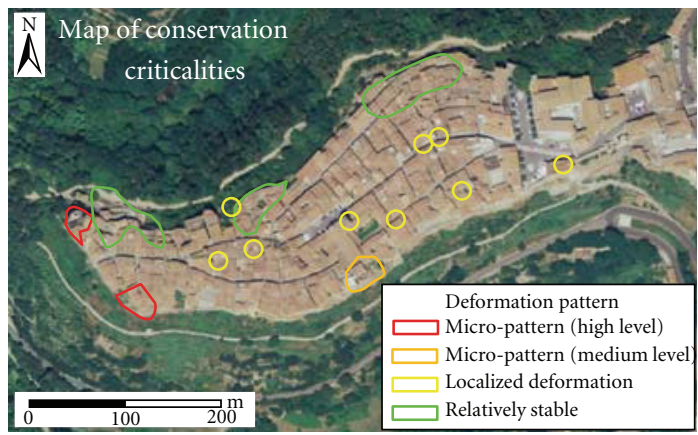

(d)

FIGURE 6: PS spatial distribution and related $V_{\text {LOS }}$ field over the Pitigliano cliff for the datasets: (a) ERS descending (1992-2000); (b) ENVISAT ascending (2003-2010); (c) ENVISAT descending (2003-2010). The PSI-based rapid mapping led to draw a map of the conservation criticalities (d), which reports the zoning of the unstable sectors and localized deformation, distinguished from the relatively stable areas.

In addition to this factor of criticality, the built heritage of Pitigliano located along the cliff edges is chronically affected by the instability mechanisms of the exposed rock surfaces, due to a combination of several weathering processes, such as chemical alteration, erosion, cryoclastism, and crack patterns opening, which progressively create the conditions for the triggering of rock falls and toppling events (Figure 4(c)). Hence, the continuous geomorphologic evolution of the cliff can be nowadays recognized as one of the main threats for the preservation of the Pitigliano heritage [35].

PSI data were specifically radar-interpreted to perform a zoning of the sectors along the cliff edges classifiable as potentially critical. At the same time, detailed time series analysis was exploited to verify if the unstable PSs identified over the historical buildings located within the town centre could highlight the occurrence of sudden displacements, to be correlated to potential collapses of subterranean cavities or predisposing conditions for near future collapses.

Despite the relevant number of the processed SAR images, the PSInSAR processing of the ERS-1/2 descending (1992-2000) data stack led to the identification of a reduced set of PSs (Table 1), whose spatial distribution does not homogeneously cover the historic centre (Figure 6(a)). Although this result partially makes the deformation analysis less spatially representative over the different sectors of the town, the ERS data are sufficient to confirm the absence, in the period 1992-2000, of deformation macropatterns referable to instability phenomena extended to the entire site. Indeed, all the ERS descending PSs show values of $V_{\text {LOS }}$ not exceeding the stability threshold $( \pm 1.5 \mathrm{~mm} / \mathrm{yr})$. This first impression of relative stability is supported by the detailed analysis of the PS time series, which in few cases highlight a slight tendency of the LOS displacements to movements going towards the satellite, only occasionally with $V_{\mathrm{LOS}}>$ $+1 \mathrm{~mm} / \mathrm{yr}$. In the absence of the corresponding ascending dataset, very low level of conservation criticality can be assigned over the whole historic centre for the period (19922000).

Passing to the more recent data, that is, the ENVISAT (2003-2010) ones, a significant increase in the total number of PS is immediately appreciable in both the ascending and descending datasets (Table 1), although their respective PS spatial distribution shows some lack over certain sectors of the town, reflecting the different acquisition geometry of the processed SAR images (Figures 6(b)-6(c)). Particularly, the ascending dataset mainly covers the central-southern parts of the town (Figure 6(b)), while the descending one results in being better distributed over the central-northern sectors (Figure 6(c)).

Being aware that the two datasets are not perfectly temporally overlapped (October 2003-May 2010 for the ascending data, May 2003-June 2010 for the descending ones), the integrated analysis of the deformation estimates highlights the presence of two micropatterns, with downwards LOS 

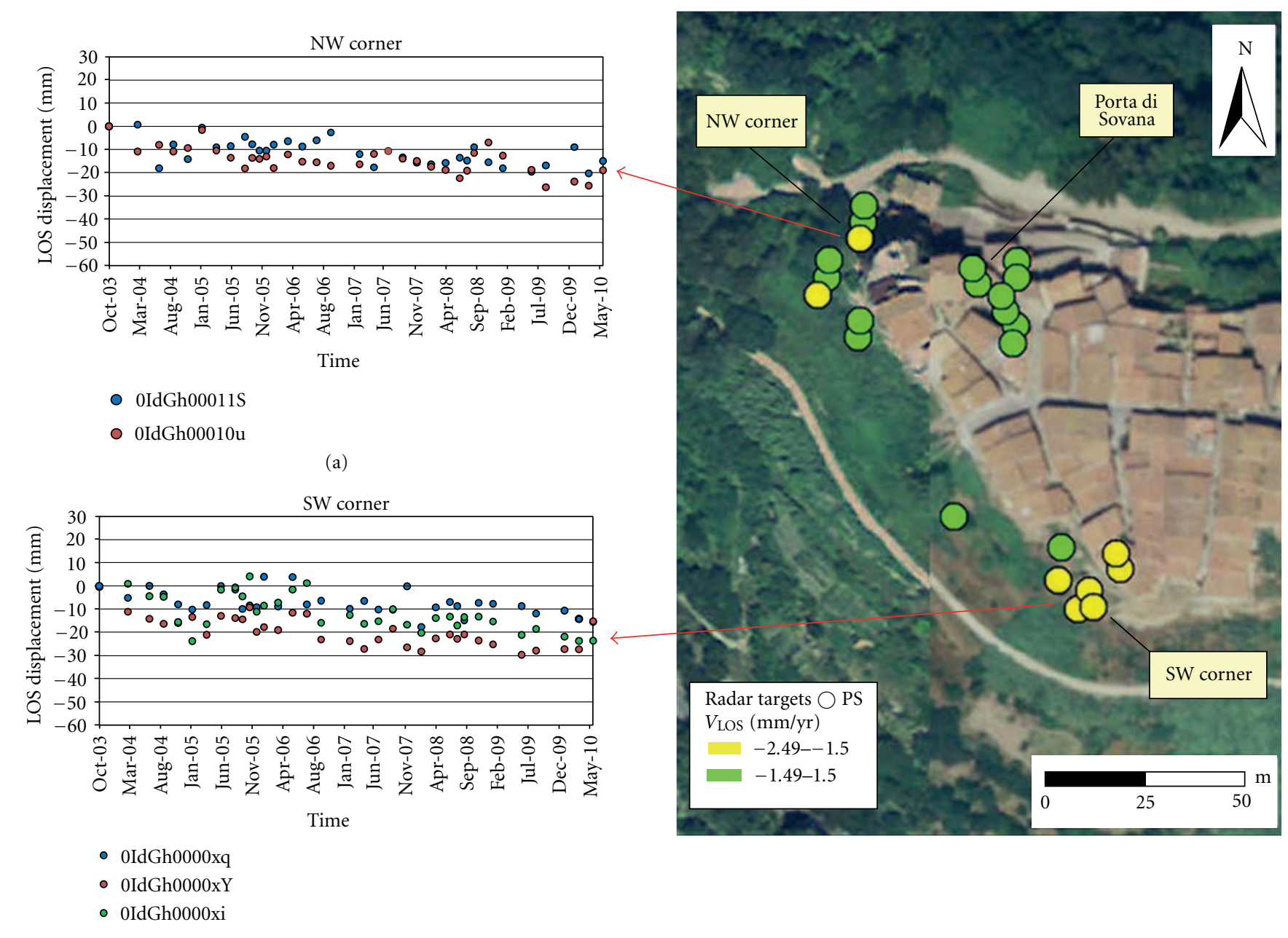

SW corner

(b)

FIgure 7: Spatial distribution and related $V_{\text {LOS }}$ field for the ENVISAT ascending (2003-2010) dataset over the western side of the Pitigliano cliff. Deformation micropatterns are identified over the north-western and south-western corners of the cliff, with downwards moving PS, whose time series are reported, respectively, in the plots (a) and (b).

displacements in the ascending data, concentrated, respectively, over the north-western and south-western corners of the cliff (Figures 6(b), 6(d), and 7).

The PS cluster over the north-western corner is characterized by two PS ENVISAT ascending (2003-2010) with $V_{\text {LOS }}$ up to $-2.1 \mathrm{~mm} / \mathrm{yr}$ (Figure 7 ), whose time series show displacement trends progressively going away from the satellite, especially since March 2005 (Figure 7(a)). Slight tendency to downwards movements is also recognizable within the time series of neighbouring PSs, which appear stable as their $V_{\text {LOS }}$ only occasionally exceed the value of $-1 \mathrm{~mm} / \mathrm{yr}$. The presence of several deformation estimates which share similar displacement trends induces to assign a medium-high level of conservation criticality to the buildings located on the north-western corner of the cliff.

On the other hand, there is no doubt to classify the builtup area on the south-western corner as highly critical (Figures 6(d) and 7), due to the significant number of downwards moving PS ENVISAT ascending (2003-2010) concentrated over the buildings and along the slope; the intensity of the detected deformation ( $V_{\mathrm{LOS}}$ up to $-2.9 \mathrm{~mm} / \mathrm{yr}$ ); the persistence, throughout the monitoring period, of a displacement trend progressively going away from the satellite (Figure 7(b)); the value of the estimated total LOS displacement (up to $-25 \mathrm{~mm}$ over approximately seven years). Also, the time series of the PS located, respectively, along the slope, close to the cliff edge and over the buildings show similar LOS displacement trends (Figure $7(\mathrm{~b})$ ).

The priority level to assign to these two sectors, as assessed based on the PSI data, is further appreciable if compared with the relative stability that both the ascending and descending ENVISAT datasets show over other sectors of the cliff, such as the area of Porta di Sovana, located just few metres from the north-western corner, along the northern edge (Figures 6(d) and 7). Here, the detailed analysis of PS time series completely excludes the occurrence of clear deformation trends potentially associable to instability processes active in the period 2003-2010. 


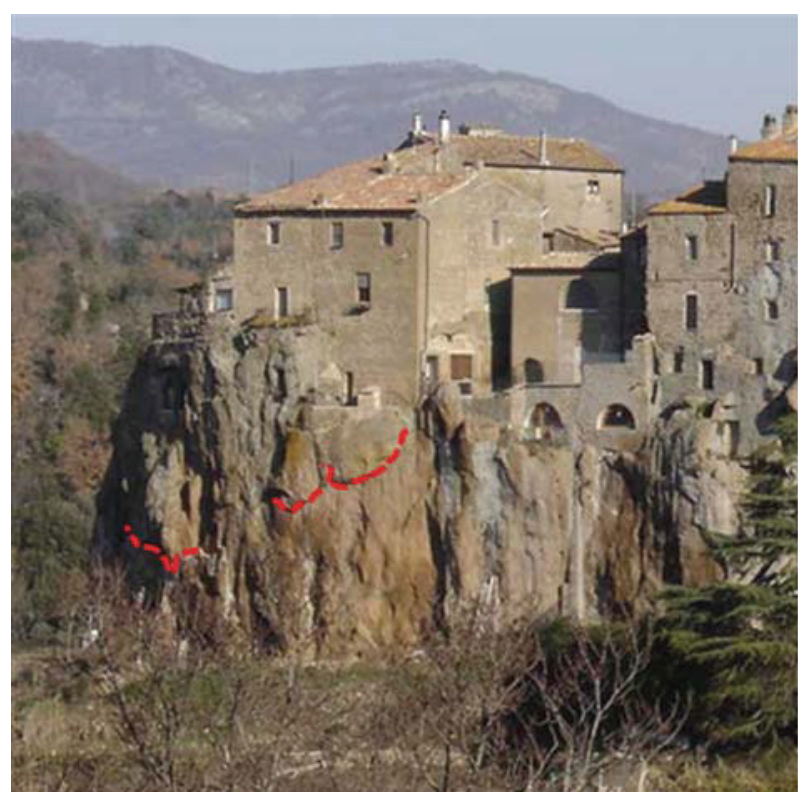

Figure 8: Detailed view of the south-western corner of the Pitigliano cliff. Close examination of the rock surfaces highlights the boundaries of rock wedges underneath the masonry walls.

As further element to strengthen the relevance of these satellite findings in the perspective of an effective early stage warning of near future instability, it is to be mentioned that both the sectors classified as unstable belong to a portion of the Pitigliano town which was historically damaged by progressive retreat of the cliff likely due to rock falls. As reported by Fanti et al. [35], a recent archive-based research comparing historical maps and old photographs has clarified that the western side of the cliff is nowadays completely modified from the past, and several buildings totally disappeared.

The high level of conservation criticality of both the sectors is also confirmed by the hazard assessment performed by Canuti and Fanti [36] and recently published by Fanti et al. [35] as 3D quantitative kinematic analysis directly performed on high detailed terrestrial laser scanning survey of the cliff. Based on these data and direct observations on the rock surfaces (Figure 8), the mechanisms known as "wedge failure," "flexural block toppling," and, secondarily, "toppling" are the highest probable for the south-western corner, while the flexural toppling is predominant for the north-western corner. In these terms, the persistence, throughout the monitoring period, of LOS displacements going away from the satellite in the ascending geometry leads not to exclude the hypothesis of tilting movements of the exposed elements as a consequence of active rock mass instability.

A second level of priority seems reasonable to be attributed to localized deformation, which was detected over single buildings located along the southern side of the cliff (orange micropattern in Figures 6(d) and 9). The similarity in terms of LOS displacement trend between a downwards moving PS with $V_{\text {LOS }}$ up to $-1.7 \mathrm{~mm} / \mathrm{yr}$ and two PSs apparently stable suggests the presence of a more extended deformation pattern (Figure 9(b)). In particular, mutually comparable records of LOS displacements are recognizable within all the respective PS time series, especially since February 2007.

Differently, the ENVISAT ascending (2003-2010) dataset does not show particular evidence of instability processes for the northern cliff side, except for a localized deformation found over an enclosed sector of buildings in the central part of the northern edge (yellow circle in Figure 6(d)). Although the poor coverage of this dataset along the northern side does not allow a complete deformation analysis to be performed, the corresponding descending data show relatively stable PS time series and suggest a quite relative stability in the period 2003-2010 (Figures 6(c)-6(d)).

Interestingly, over several buildings within the town centre, the time series of downwards moving PS ENVISAT ascending (2003-2010) do not reveal the occurrence of significant accelerations. No evidences of sudden displacements due to cavities collapses are found (Figures 6(b) and 9). Indeed, most of the PS time series are characterized by LOS displacement trends progressively going away from the satellite, with $V_{\text {LOS }}$ up to $-2.2 \mathrm{~mm} / \mathrm{yr}$ (Figure 9 (a)). If on one hand this evidence does not give proof about past/recent instability events, on the other hand it is not to be excluded that further SAR acquisitions after the last updating of the analyzed PSI data (i.e., May 2010) could confirm the evolution of these progressive displacement trends. Hence, on-site checks and terrestrial surveys, performed also within the subterranean cavities underneath the buildings, seem to be a necessary step to validate and correctly interpret the data.

Similar considerations are also valid for the time series of the single downwards moving PS identified in the ENVISAT descending data (2003-2010) in the middle of the town centre (Figure 6(c)).

3.3. Rural Sites: Bivigliano, Northern Tuscany (Italy). Sited $20 \mathrm{~km}$ north of Florence in the municipal territory of Vaglia, the countryside settlement of Bivigliano is mainly built along the western slope of the mountain called Monte Senario (Figure 5). Geologically, the site is founded on Holocene colluvial sediments overlying the bedrock constituted by the Monte Senario Sandstones Formation, that is, Middle-Lower Eocene feldspathic-quartz sandstones containing coarse quartz pebbles, mica, phyllite, and calcareous material. In terms of historic and artistic heritage, since medieval times the parish church (Figure 5(a)) based in Bivigliano was a landmark for the social life of all the territory and, starting from the XIII century, it was flanked by the neighbouring Convent of Monte Senario (Figure 5(b)). Despite this ancient origin (the name "Bivigliano" derives from a member of the Medici family, already powerful in the Medieval-Renaissance Florence), the current urban arrangement of Bivigliano was strongly influenced by the recent history. The village was a renowned place for holidays since the end of the XIX century and flourished with a significant urban development phase in the decades 1900-1950s. In this period, for instance, the 

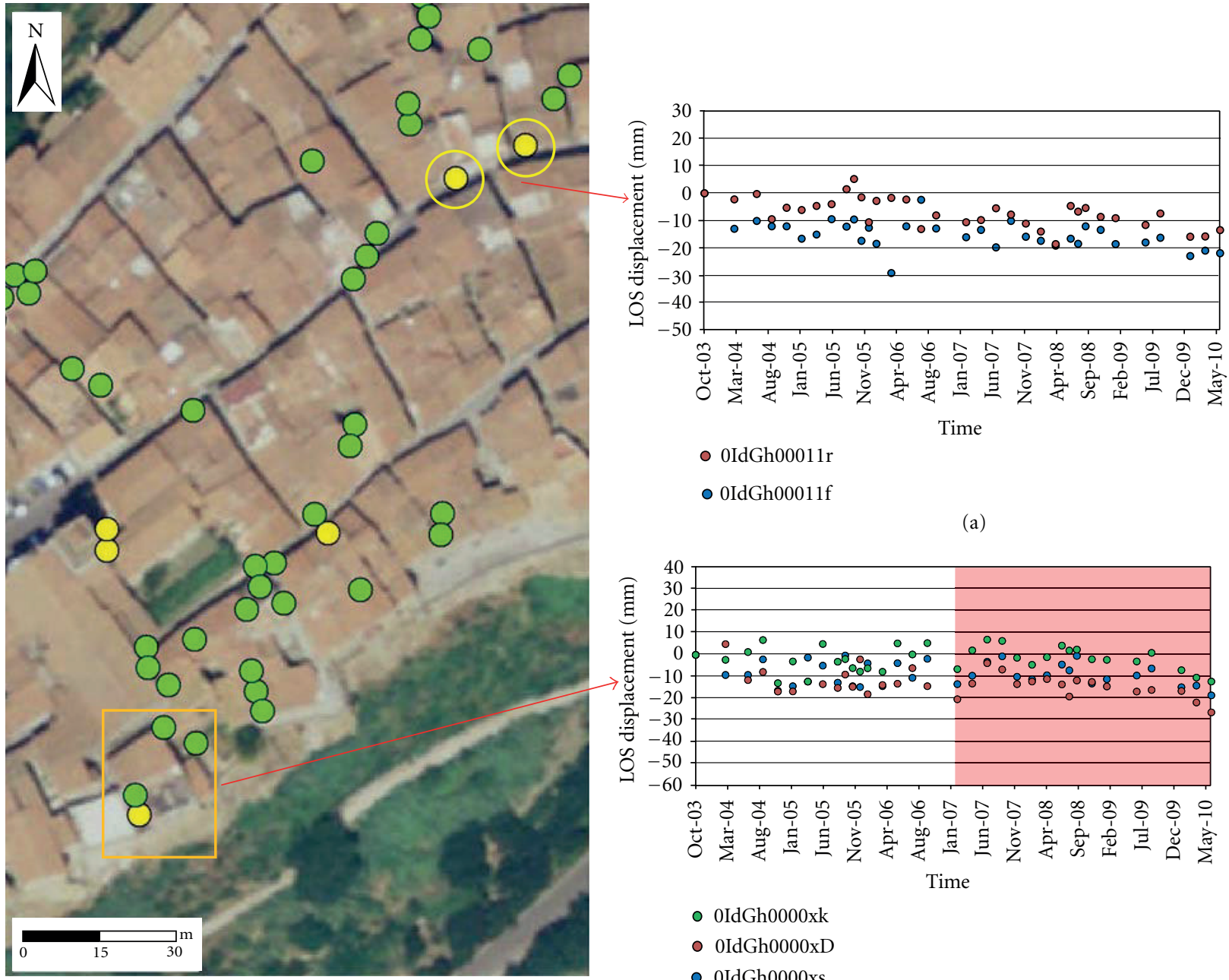

0IdGh00011r

- 0IdGh00011f

(a)

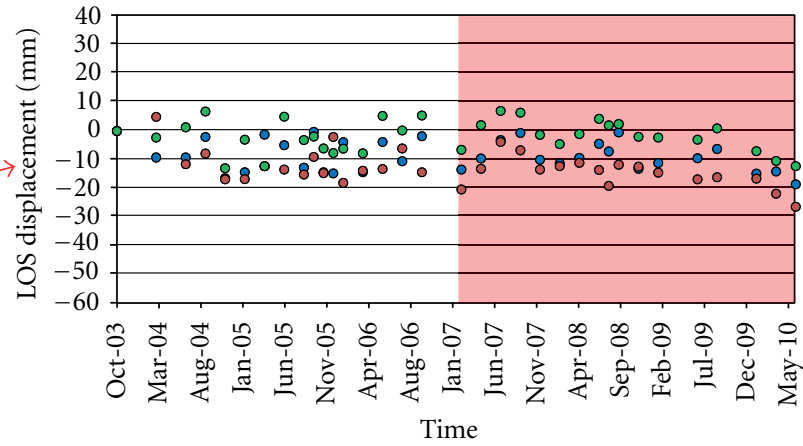

- 0IdGh0000xk

- 0IdGh0000xD

- 0IdGh0000xs

(b)

FIGURE 9: Spatial distribution and related $V_{\text {LOS }}$ field for the ENVISAT ascending (2003-2010) dataset over the central-eastern part of the Pitigliano town centre. Localized deformation is identified over some buildings, with downwards moving PS showing a progressive LOS displacement trend away from the satellite (a), while one downwards moving PS and some apparently stable PSs located close to the cliff edge share a common LOS displacement trend, especially since February 2007 (b).

road still connecting the village with the Monte Senario convent was cut along the slope. Among the built heritage of Bivigliano are to be mentioned the Church of San Romolo (Figure 5(a)), the late XVI century noble residency called Villa Pozzolini (or "Villa di Bivigliano"; Figure 5(c)), and the Monte Senario convent itself (Figure 5(b)). All these historical evidences are still inserted within a landscape context, which is nowadays one of the main features to be preserved.

Nevertheless, effective strategies of land management have to tackle the landslide susceptibility of the territory, as testified from different historical records of terrain motions and ground instability, such as the "landslide of Bivigliano" mentioned in a document and which occurred in 1729 [37]. Indeed, several landslide bodies are also reported in the Regional Geological Map (Carta Geologica Regionale
(CGR)) Sheet 263120 scale 1:10,000 (Figure 10), as well as in the Italian Landslide Inventory (Inventario Fenomeni Franosi in Italia (IFFI)) produced by the Italian Institute for Environmental Protection and Research in 2007. Due to landslipping, in modern times the old cemetery of the village was moved to the present place (area d in Figure 5).

In light of these conservation issues, the feasibility test was aimed at exploiting the PSI data to assess the evolution of the condition for the main monuments and historical buildings of Bivigliano since 1992, within the broader environmental context and related deformation patterns.

At the scale of entire site, the multitemporal analysis of the PS spatial distribution of both the ERS and ENVISAT datasets highlights the persistence, from the historical period (1992-2000) to the recent one (2003-2010), of an extended deformation macropattern covering most of the residential 


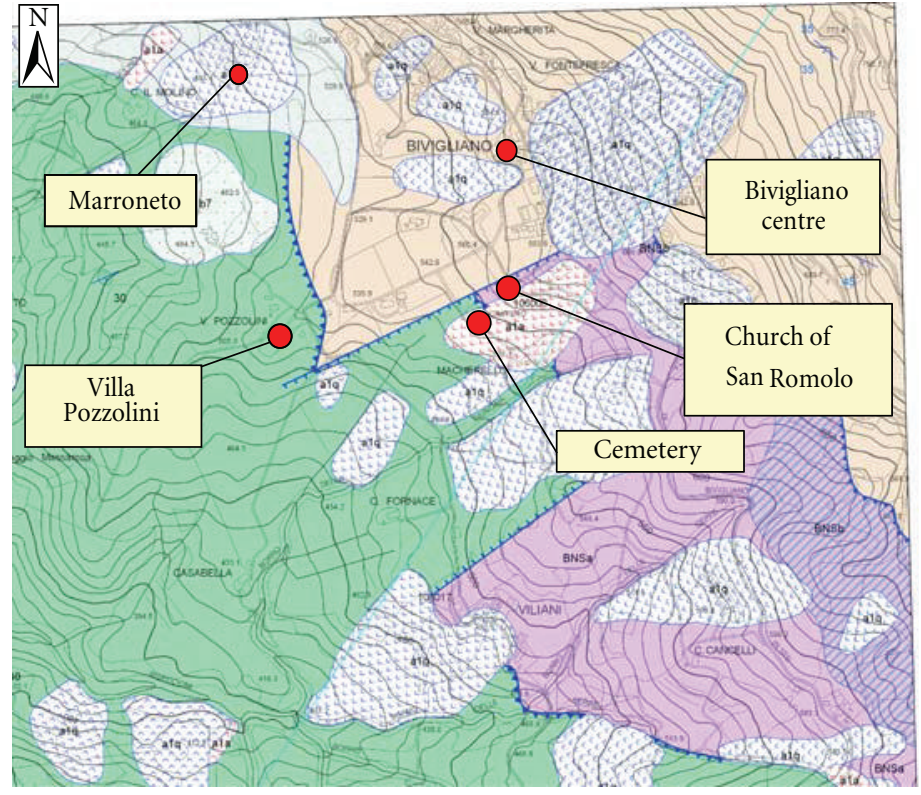

(a)

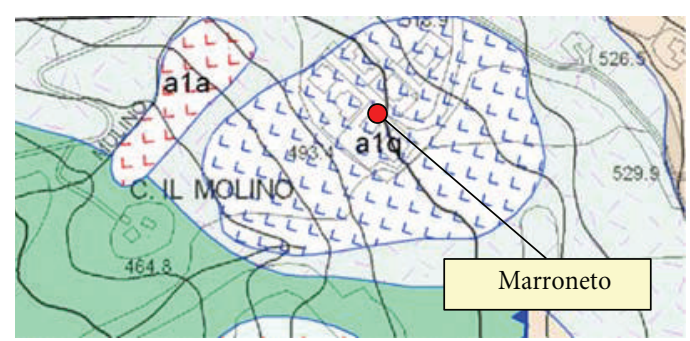

(b)

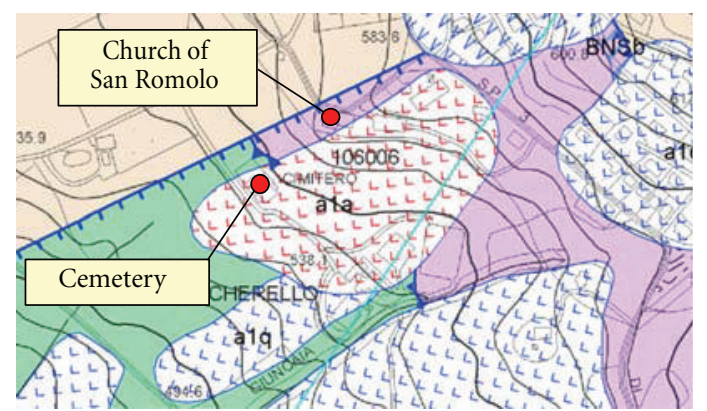

(c)

Landslide type-state of activity
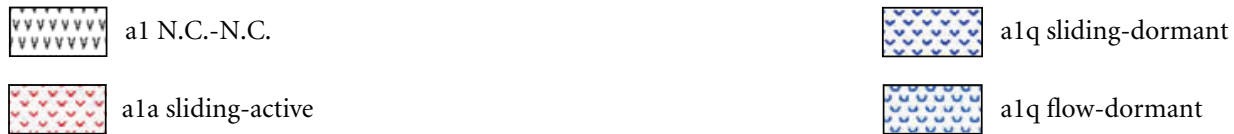

Figure 10: (a) Detail of the Regional Geological Map Sheet 263120 scale 1: 10,000 over the Bivigliano territory, with the landslide inventory reporting several landslide bodies, among which: (b) dormant slide over Marroneto; (c) active slide close to the church and including the cemetery.

sectors of Bivigliano, with LOS displacement field mainly characterized by movements going away from the satellite (Figure 11). This deformation macropattern is clearly detected in both ERS descending (1992-2000) and ENVISAT descending (2003-2010) datasets (Figures 11(a) and 11(c)), while in the ENVISAT ascending (2003-2010) dataset only few and isolated PSs show $V_{\mathrm{LOS}}$ exceeding the stability threshold $( \pm 1.5 \mathrm{~mm} / \mathrm{yr}$; Figure 11(b)).

In particular, for the ERS descending (1992-2000) data, the modal value (i.e., the value that occurs most frequently) of coherence is 0.73 , with $35 \%$ of the identified MP assuming coherence values $\geq 0.80$. The associated $V_{\mathrm{LOS}}$ field spans from -8.8 to $-0.5 \mathrm{~mm} / \mathrm{yr}$, with a $V_{\mathrm{LOS}}$ modal value of $-2.2 \mathrm{~mm} / \mathrm{yr}$. On the other hand, the ENVISAT descending (2003-2010) data, here used as recent dataset, shows coherence modal value of 0.76 , with $25 \%$ of the identified PS assuming coherence values $\geq 0.78$. The associated $V_{\text {LOS }}$ field ranges from -4.7 to $-1.2 \mathrm{~mm} / \mathrm{yr}$, with a $V_{\mathrm{LOS}}$ modal value of $-1.0 \mathrm{~mm} / \mathrm{yr}$.

These simple statistics confirm the impression of a less concentrated and intense deformation macropattern covering the settlement during the period 2003-2010, than the corresponding one observed in the historical data (19922000). Nevertheless, both the datasets suggest a potential correlation between the spatial distribution of most of the identified PS clusters and the presence of landslide bodies, especially if considering the boundaries and extent of the landslide phenomena mapped in the previously mentioned CGR scale 1:10,000 (Figures 10 and 11). At the same time, the PS spatial distribution of the ERS and ENVISAT descending data opens to the need of an accurate updating of the knowledge basis about the current state of activity of the already mapped landslide phenomena. Such analysis will clarify whether the deformation detected from the satellite can be attributed only to natural hazards or also to humaninduced impacts (e.g., water pumping).

In these terms, it is quite interesting to note the persistence of a deformation micropattern since 1992 over the peripheral area of Bivigliano called Marroneto (Figures 11 and 12), historically occupied by the local craftsmen and located north-west of the main residential quarter (area (e) in Figure 5). Here, the CGR reports the presence of a huge landslide body classified as "dormant slide" ("frana di scorrimento quiescente"; Figure 10(b)).

Over there, the ERS descending (1992-2000) data show a concentrated micropattern consisting of four downwards moving PS (Figure 12(a)), with $V_{\text {LOS }}$ up to $-5.1 \mathrm{~mm} / \mathrm{yr}$ and a linear displacement trend progressively going away from the satellite, reaching a total value of LOS displacement up to $-50 \mathrm{~mm}$ over approximately eight years (Figure 12(d)). Not less severe is the corresponding micropattern observable in the ENVISAT descending (2003-2010) data (Figure 12(c)). 


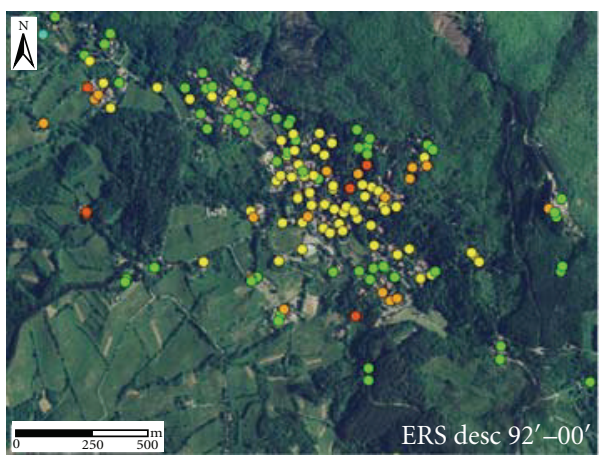

(a)

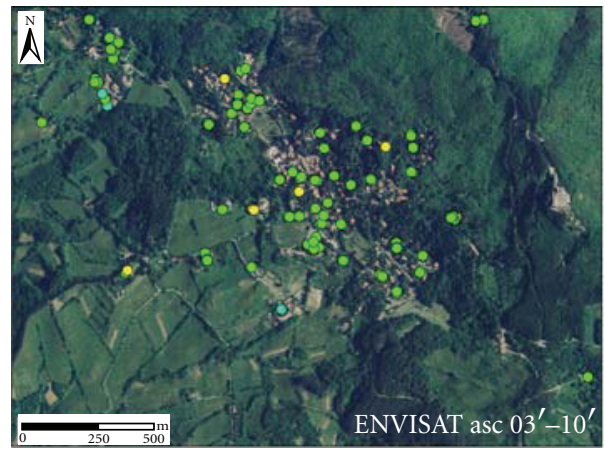

(b)

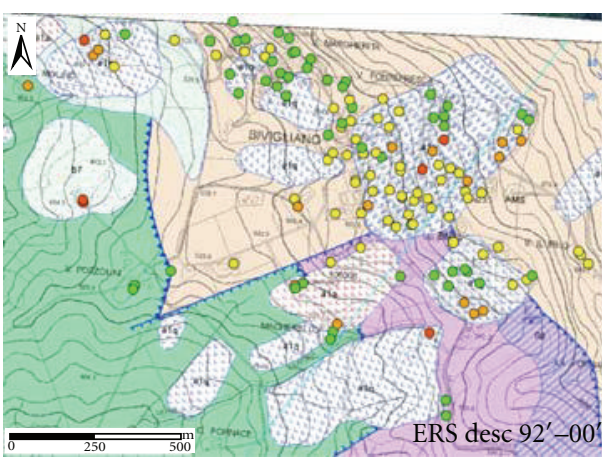

(d)

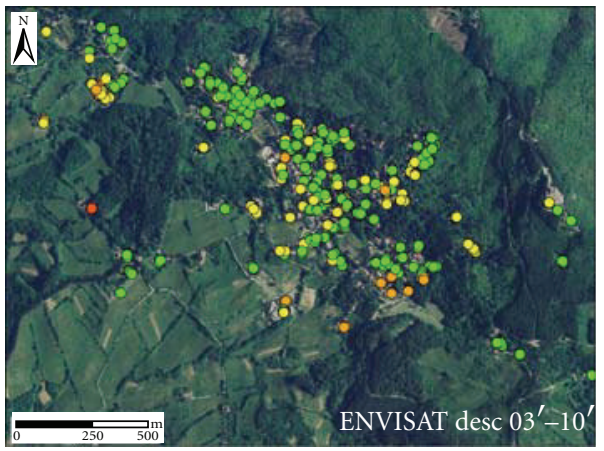

(c)

Radar targets $\bigcirc$ PS

LOS velocity $(\mathrm{mm} / \mathrm{yr})$
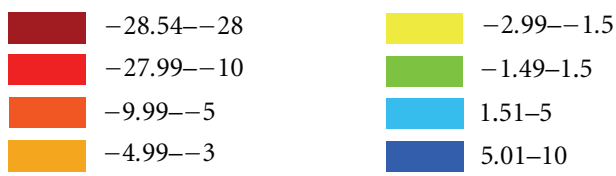

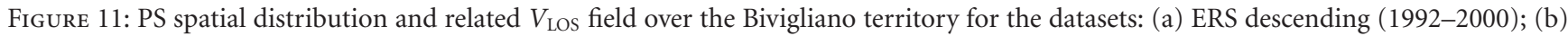
ENVISAT ascending (2003-2010); (c) ENVISAT descending (2003-2010). Superimposition of PS datasets over the landslide inventory (see Figure 10) suggests a potential correlation with the distribution and extent of the mapped landslides, as perceivable observing the ERS data (d).

Nineteen downwards moving PSs were identified over the whole area, with $V_{\mathrm{LOS}}$ ranging from -5.3 to $-1.5 \mathrm{~mm} / \mathrm{yr}$, and modal value of $-3.7 \mathrm{~mm} / \mathrm{yr}$. All the PS time series share the same LOS displacement trend, which progressively goes away from the satellite throughout the monitoring period (Figure 12(f)), with a progression not as linear as that found in the time series of the historical ERS descending data (Figure 12(d)). The total LOS displacement reaches up to $-45 \mathrm{~mm}$ over about seven years. Correspondingly, despite the reduced number of the identified PS, the ENVISAT ascending (2003-2010) dataset shows a localized micropattern consisting of two isolated upwards moving PSs (Figure 12(b)), with $V_{\mathrm{LOS}}$ of $+1.8 \mathrm{~mm} / \mathrm{yr}$ and LOS displacement trends characterized by an annual seasonal component of about $5 \mathrm{~mm}$ (Figure 12(e)).

Passing to the scale of single building, the ancient and modern built heritage of Bivigliano is characterized by differential conditions in terms of PSI-based levels of conservation criticality. The worst situation was found for the Church of San Romolo (Figure 13). Although it is only a single PS not surrounded by other deformation estimates, the downwards moving PS ERS descending (1992-2000) identified over the bell tower of the church (Figure 13(a)) assumes a particular relevance, especially if analyzed in integration with the more recent PSI data (Figure 13(c)). This PS shows a $V_{\mathrm{LOS}}$ of $-2.2 \mathrm{~mm} / \mathrm{yr}$ and an approximately linear LOS displacement trend progressively going away from the satellite until March 1999 (Figure 13(b)).

While a lack of PS characterizes the ENVISAT ascending (2003-2010) dataset, a clear deformation micropattern affects the entire complex of the church in the corresponding descending (2003-2010) dataset (despite the shift in the PS georeferencing; Figure 13(c)). All the five identified PSs, including the one which appears stable, share a common LOS displacement trend going progressively away from the satellite, with $V_{\mathrm{LOS}}$ reaching the maximum value of $-2.7 \mathrm{~mm} / \mathrm{yr}$ and a total LOS displacement up to $-20 \mathrm{~mm}$ over approximately seven years (Figure 13(d)). These satellite evidences confirm a high level of conservation criticality for the entire architectural complex.

Indeed, the recent history of the church and on-site inspections provide a strong validation of the analyzed PSI 

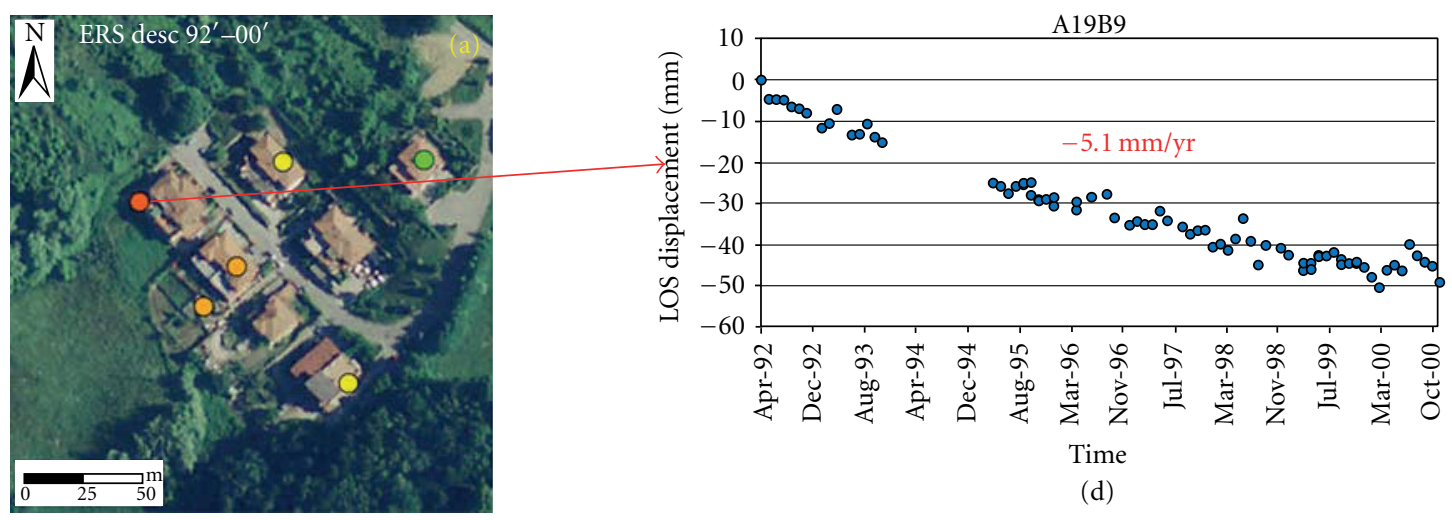

(d)
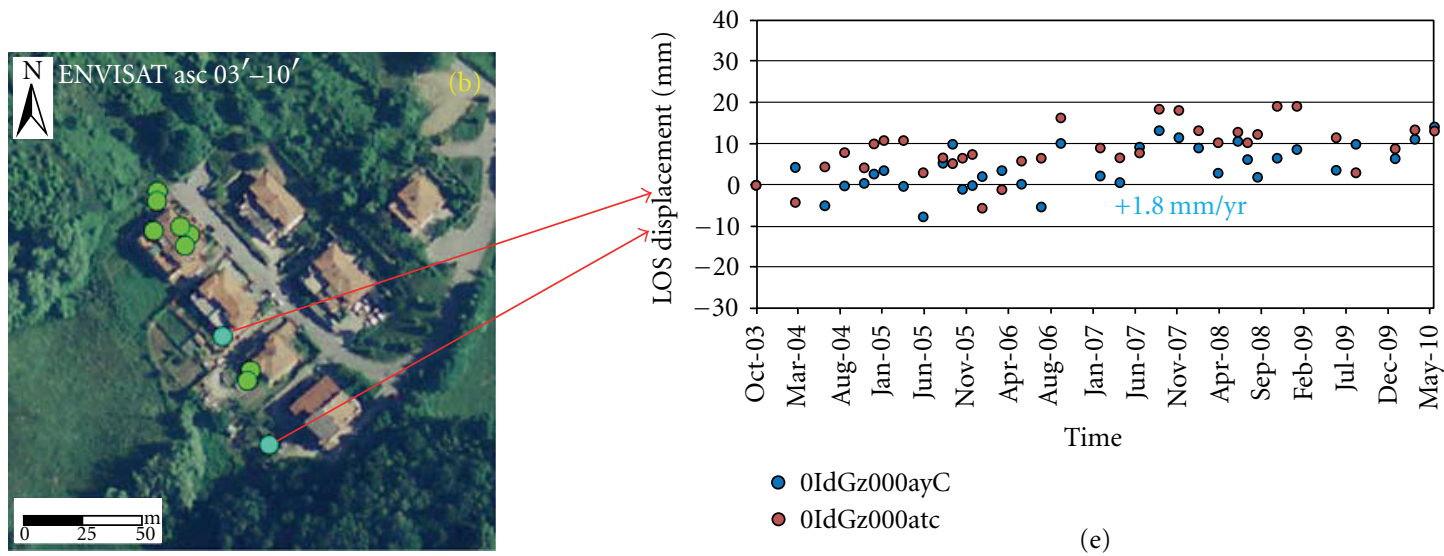

- 0IdGz000ayC

- 0IdGz000atc

(e)
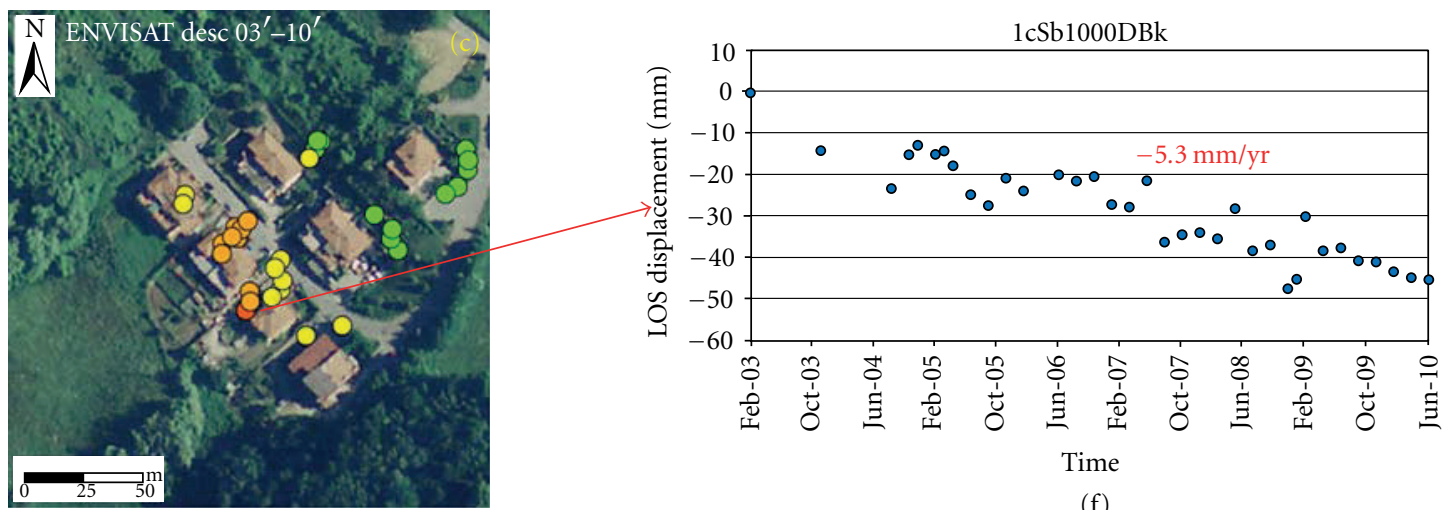

(f)

FIGURE 12: PS spatial distribution and related $V_{\text {LOS }}$ field over Marroneto for the datasets: (a) ERS descending (1992-2000); (b) ENVISAT ascending (2003-2010); (c) ENVISAT descending (2003-2010), associated to examples of time series representative of the respective LOS displacement trends $((\mathrm{d})-(\mathrm{f}))$.

data. During the monitoring period (1992-2010), several interventions of stabilization and consolidation were carried out by the local authorities and heritage bodies. Particularly, substantial repairs were carried out between 1990s and 2000s on the containing wall, which supports and protects the substratum on which the church is founded.

Nevertheless, new cracks recently opened and currently cross over the pavement in front of the main entrance of the church. Also, new fissures progressively developed on the brick floor inside the church, starting from the main entrance and reaching the middle of the nave and the southern wall, as well as huge cracks which run on both the exterior and interior façades (Figure 13(f)).

Curiously, looking at the landslide inventory reported in the CGR, the boundary of an "active slide" ("frana di scorrimento attiva") runs close to the church but does not include it (Figure 10(c) and red dashed line in Figure 13(a) and 13(c)). Based on the PSI data and ground truth, it seems reasonable to propose a modification of the landslide boundaries, to be extended also to the area of the church. Execution of detailed ground investigations might be preparatory to the design of appropriate consolidation 

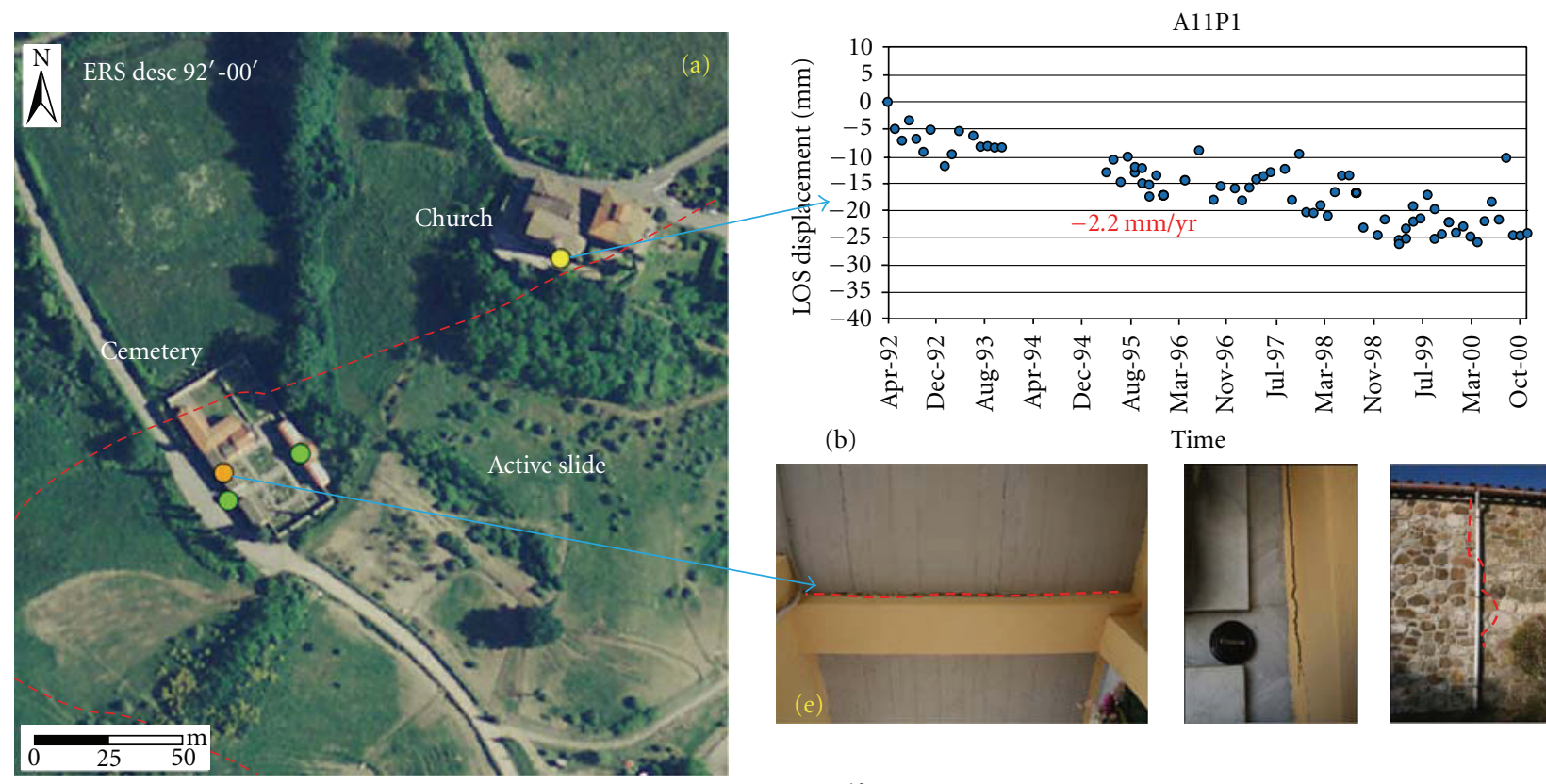

(b)
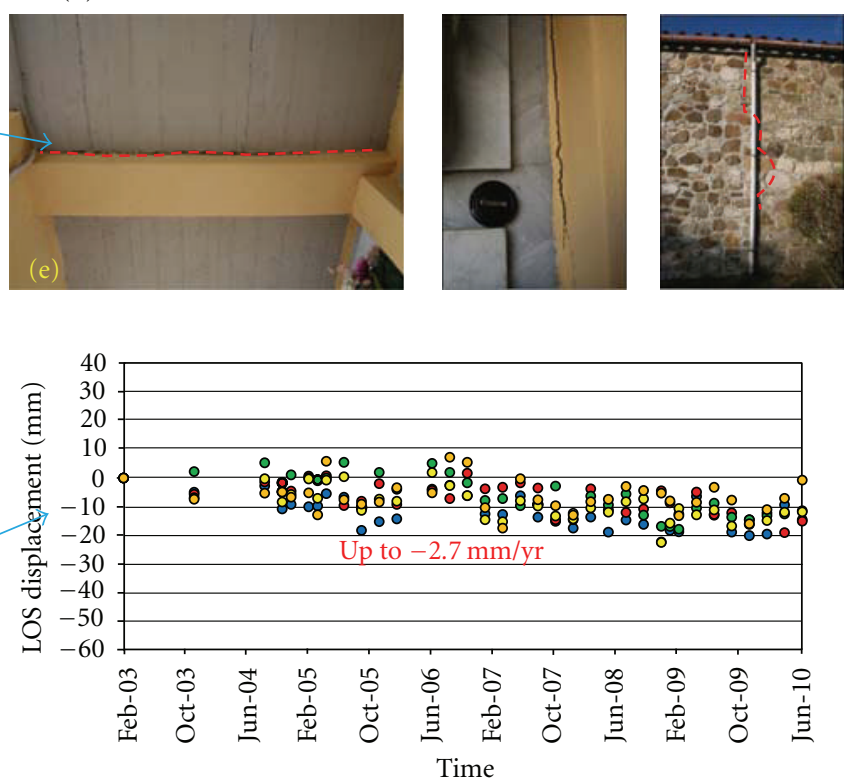

1cSb1000DaX

- 1cSb1000Daw

(d)

○ $1 \mathrm{cSb} 1000 \mathrm{DbI}$
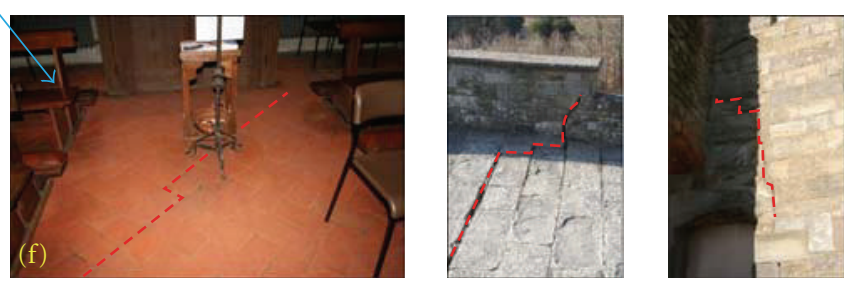

FIGURE 13: PS spatial distribution and related $V_{\text {LOS }}$ field over the Church of San Romolo and the cemetery for the datasets: (a) ERS descending (1992-2000) with (b) a single downwards moving PS in correspondence with the bell tower; (c) ENVISAT descending (2003-2010), with several downwards moving PSs sharing a common LOS displacement trend (d). Severe crack patterns affect the exterior and interior wall surfaces and floor of both the cemetery (e) and the church of San Romolo (f). The red dashed line in (a) and (c) marks the boundary of an active slide mapped in the inventory of the CGR (cf. Figure 10).

works, at the level of both the unstable ground and the deteriorated structures.

The same active slide actually includes most of the modern cemetery, located south of the church, along the slope (Figure 10(c)). Again, the ERS descending (1992-2000) and ENVISAT descending (2003-2010) datasets suggest the presence of superficial deformations which might be the effects of landsliding phenomena and consequent structural instability of the masonries (Figure 13(a) and 13(c)). A single
PS with a linear LOS displacement trend going away from the satellite shows a $V_{\text {LOS }}$ of $-3.5 \mathrm{~mm} / \mathrm{yr}$, and it is coupled with an apparently stable PS. The latter is characterized by a phase of downwards movements until May 1999, followed by an upwards phase till November 2000. Both the PSs are located over the southern wall of the cemetery (Figure 13(a)).

Differently from the ENVISAT ascending (2003-2010) data where a lack of PS affects most of the area of the cemetery, the corresponding ENVISAT descending data 


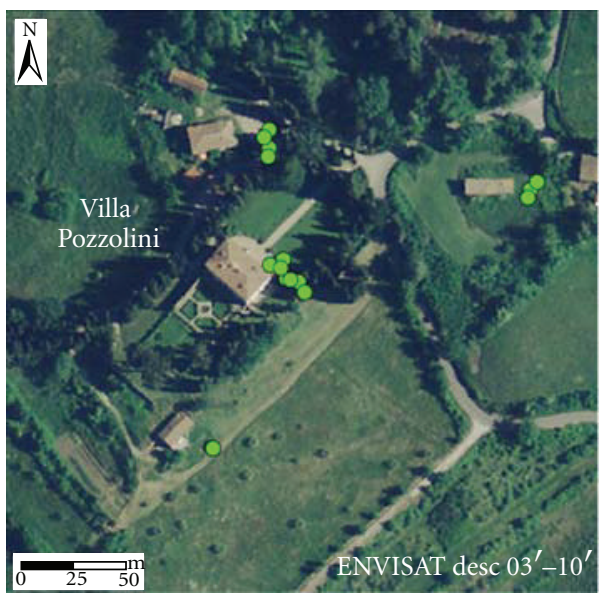

(a)

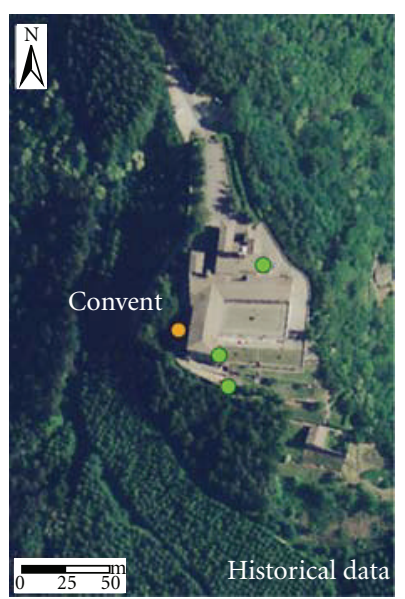

(b)

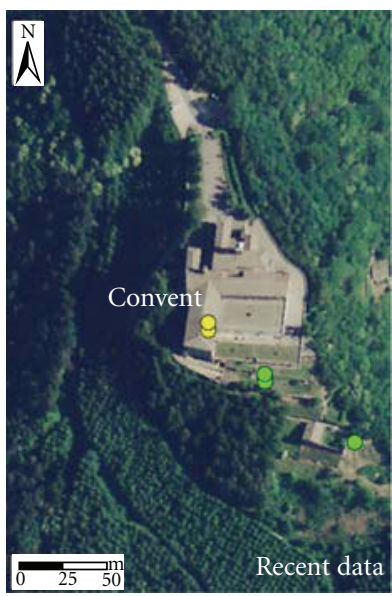

(c)

FIGURE 14: (a) Spatial distribution and related $V_{\text {LOS }}$ field of the ENVISAT descending (2003-2010) dataset confirm a relative stability for Villa Pozzolini and surroundings, while the comparison between (b) historical data (ERS descending 1992-2000) and (c) recent ones (ENVISAT descending 2003-2010) over the Convent of Monte Senario highlights the persistence of localized deformation over the southern part of the complex.

highlight a slight tendency to downwards LOS displacements throughout the monitoring period within the time series of all the three identified PSs.

Although the reduced number of the identified PS and their spatial configuration lead to consider them only localized deformation, a stronger evidence to validate these satellite findings can be retrieved from on-site checks. The crack pattern survey over the concrete and stonefaced masonries of both the southern and northern walls highlights a good agreement between the spatial distribution of the fissures and the PS positions (Figure 13(e)). The cracks mainly developed in correspondence with the conjunction of masonries related to different phases of construction, that is, the weakest structural points on which active landslide events can have higher impacts.

Conversely, low levels of conservation criticalities are to be assigned to the monumental complexes of Villa Pozzolini and the Convent of Monte Senario (Figure 14). In the first case, all the three analyzed PS datasets show a quite relative stability over the Villa, as well as for the surrounding buildings and the homestead in front of the Villa which belong to the estate. This is particularly observable in the ENVISAT descending (2003-2010) dataset, which is the most completed one in terms of PS spatial distribution (Figure 14(a)). Nevertheless, this dataset clearly exemplifies the issue that sometimes an operator could find, that is, the error in the PS georeferencing and consequent shift of the PS with respect to the orthophoto used as visual reference. In this case, the shift is very easily appreciable by comparing the spatial configuration of the identified PS clusters and the geometry of the buildings to which the PSs are reasonably to be referred.

Similarly, no relevant deformation patterns are detected over the Convent of Monte Senario, except for one single PS ERS descending (1992-2000) with $V_{\text {LOS }}$ of $-3.4 \mathrm{~mm} / \mathrm{yr}$ and an almost constant linear trend throughout the monitoring period, reaching a total LOS displacement of $-40 \mathrm{~mm}$ over eight years (Figure 14(b)). The impression that this deformation is to be recognized as a localized deformation is confirmed by the persistence of downwards LOS displacements also within the time series of two PS ENVISAT descending (2003-2010), located over the southern part of the convent (Figure 14(c)). These PSs share a common LOS displacement trend progressively going away from the satellite and reach a total LOS displacement of about $-15 \mathrm{~mm}$ over eight years, associated to a $V_{\mathrm{LOS}}$ of, respectively, -2.5 and $-2.2 \mathrm{~mm} / \mathrm{yr}$.

\section{Conclusions}

The methodology of rapid mapping and deformation analysis proposed here has the potential to become a routine tool to be increasingly employed by the practitioners and heritage bodies, in support of the ordinary activities of noninvasive diagnosis and preservation of cultural heritage, both concentrated within enclosed areas (e.g., historic centres) and spread within urban and rural environments. The implementation of PSI-based analyses is also expected to be more and more complementary to the activities of built heritage management, in the framework of broader strategies of land planning.

The feasibility tests discussed in this paper confirm these potentials of the PSI techniques, especially for the purposes of preventive diagnosis, thanks to the capability of detecting superficial deformation as indicators of ongoing deterioration phenomena, or even evolving processes which might develop into severer instability events. Such diagnostic feature is further enriched by the possibility of back monitoring the displacement field of the AOI up to 1992 with the ERS-1/2 imagery, thereby reconstructing the deformational behaviour of the observed phenomena during a sufficiently long period of observation. 
Nevertheless, some drawbacks can arise, such as the lack of PS over the AOI while passing from a dataset to another, especially if the analyzed datasets are acquired from different satellite platforms. The reduced number of identified PSs over the elements of major interest and even the total absence of deformation estimates, respectively, limit and inhibit the execution of a reliable and complete deformation analysis. Frequently, the deformational behaviour is actually assessed based on one of the two acquisition geometries (ascending or descending), and, consequently, the retrieved information can be only referred to the LOS component of the real displacement vector which represents the deformation affecting the radar targets. This issue is only partially solvable by refining the processing setting and better focusing the scale of analysis, but not always significant improvements are achieved. Certainly, the installation of corner reflectors over the AOI and in correspondence with the buildings to monitor is a feasible solution but requires additional costs, is not retroactive before the date of installation, and implies issues in terms of landscape impacts on the monuments.

Although the PSI data radar-interpreted here were not formerly processed for cultural heritage applications, both the feasibility tests of rapid mapping provide interesting results, showing a good agreement between the satellite evidences and the ground truth, as well as the information retrieved from previous research (case of Pitigliano) and existing mapping products (case of Bivigliano). With reference to this second case, the PSI data also demonstrated their potential to provide informational elements to update the background knowledge, suggesting, for instance, a review of the landslide inventory.

In terms of selective analysis of differential conditions, the PSI data over Pitigliano led to zone the most unstable sectors of the built-up areas along the cliff edges, while those covering the territory of Bivigliano allowed localized criticalities to be identified over some historical buildings rather than others, within the broader context of deformation patterns detected at the scale of entire site.

In light of the good results retrieved on ERS-1/2 and ENVISAT data stacks at medium spatial resolution and monthly sampling, further advances in such PSI-based feasibility tests are represented by experiments on PS obtained from the PSI processing of SAR imagery characterized by higher spatial and temporal resolutions.

Undoubtedly, the collection of ground truth and the integration with ancillary data and background information still remain essential elements, without which the radar interpretation of the PSI data might be affected by misinterpretation risks, especially in relation to the distinction between related and unrelated PSs (the latter correspond to PS actually not attributable to radar targets belonging to the element of interest). In this regard, the high level of agreement between the satellite evidences and other source data found during the two feasibility tests encourages the implementation of the experimented PSI techniques, also in the perspective of addressing the execution of terrestrial survey activities and the planning of targeted mitigation works, with consequent benefits in terms of cost effectiveness and sustainability.

\section{Acknowledgments}

PSI data were processed in the framework of the Extraordinary Plan of Environmental Remote Sensing (EPRS-E) project and made available through the WMS service of the Italian Ministry of Environment, Territory and Sea. Access to the Regional Geological Map (Carta Geologica Regionale (CGR)) Sheet 263120 scale 1:10,000 was performed through the Geoportal of Lamma Consorzio (http://geoportale.lamma.rete.toscana.it/).

\section{References}

[1] D. Massonnet and K. L. Feigl, "Radar interferometry and its application to changes in the earth's surface," Reviews of Geophysics, vol. 36, no. 4, pp. 441-500, 1998.

[2] P. A. Rosen, S. Hensley, I. R. Joughin et al., "Synthetic aperture radar Interferometry," Proceedings of the IEEE, vol. 88, no. 3, pp. 333-382, 2000.

[3] D. Massonnet, K. Feigl, M. Rossi, and F. Adragna, "Radar interferometric mapping of deformation in the year after the Landers earthquake," Nature, vol. 369, no. 6477, pp. 227-230, 1994.

[4] C. Squarzoni, C. Delacourt, and P. Allemand, "Nine years of spatial and temporal evolution of the La Valette landslide observed by SAR interferometry," Engineering Geology, vol. 68, no. 1-2, pp. 53-66, 2003.

[5] A. M. Goudarzi, T. Woldai, and V. A. Tolpekin, "Surface deformation caused by April 6th 2009 earthquake in L'Aquila (Italy): a comparative analysis from ENVISAT ASAR, ALOS PALSAR and ASTER," International Journal of Applied Earth Observation and Geoinformation, vol. 13, no. 5, pp. 801-811, 2011.

[6] S. Bianchini, F. Cigna, G. Righini, C. Proietti, and N. Casagli, "Landslide HotSpot mapping by means of persistent scatterer interferometry," Environmental Earth Sciences. In press.

[7] H. Rott and T. Nagler, "The contribution of radar interferometry to the assessment of landslide hazards," Advances in Space Research, vol. 37, no. 4, pp. 710-719, 2006.

[8] F. Gutiérrez, J. P. Galve, P. Lucha, C. Castañeda, J. Bonachea, and J. Guerrero, "Integrating geomorphological mapping, trenching, InSAR and GPR for the identification and characterization of sinkholes: a review and application in the mantled evaporite karst of the Ebro Valley (NE Spain)," Geomorphology, vol. 134, no. 1-2, pp. 144-156, 2011.

[9] S. Stramondo, F. Bozzano, F. Marra et al., "Subsidence induced by urbanisation in the city of Rome detected by advanced InSAR technique and geotechnical investigations," Remote Sensing of Environment, vol. 112, no. 6, pp. 3160-3172, 2008.

[10] F. Cigna, B. Osmanoğlu, E. Cabral-Cano et al., "Monitoring land subsidence and its induced geological hazard with synthetic aperture radar interferometry: a case study in Morelia, Mexico," Remote Sensing of Environment, vol. 117, pp. 146$161,2012$.

[11] M. Crosetto, O. Monserrat, and G. Herrera, "Urban applications of persistent scatterer interferometry," Radar Remote Sensing of Urban Areas, Remote Sensing and Digital Image Processing, vol. 15, pp. 233-248, 2010.

[12] F. Cigna, C. Del Ventisette, V. Liguori, and N. Casagli, "Advanced radar-interpretation of InSAR time series for mapping and characterization of geological processes," Natural Hazards and Earth System Science, vol. 11, no. 3, pp. 865-881, 2011. 
[13] G. Gigli, W. Frodella, F. Mugnai et al., "Instability mechanisms affecting cultural heritage sites in the Maltese Archipelago," Natural Hazards and Earth System Sciences, vol. 12, no. 6, pp. 1883-1903, 2012.

[14] P. Teatini, L. Tosi, T. Strozzi et al., "Resolving land subsidence within the Venice Lagoon by persistent scatterer SAR interferometry," Physics and Chemistry of the Earth, Parts $A / B / C$, vol. 40-41, pp. 72-79, 2012.

[15] M. Costantini, A. Iodice, L. Magnapane, and L. Pietranera, "Monitoring terrain movements by means of sparse SAR differential interferometric measurements," in Proceedings of the International Geoscience and Remote Sensing Symposium (IGARSS'00), pp. 3225-3227, Honolulu, Hawaii, USA, July 2000.

[16] A. Ferretti, C. Prati, and F. Rocca, "Permanent scatterers in SAR interferometry," IEEE Transactions on Geoscience and Remote Sensing, vol. 39, no. 1, pp. 8-20, 2001.

[17] A. Ferretti, A. Fumagalli, F. Novali, C. Prati, F. Rocca, and A. Rucci, "A new algorithm for processing interferometric data-stacks: SqueeSAR," IEEE Transactions on Geoscience and Remote Sensing, vol. 49, no. 9, pp. 3460-3470, 2011.

[18] C. Werner, U. Wegmüller, T. Strozzi, and A. Wiesmann, "Interferometric point target analysis for deformation mapping," in Proceedings of the IGARSS: Learning From Earth's Shapes and Colours, pp. 4362-4364, Toulouse, France, July 2003.

[19] A. Hooper, H. Zebker, P. Segall, and B. Kampes, "A new method for measuring deformation on volcanoes and other natural terrains using InSAR persistent scatterers," Geophysical Research Letters, vol. 31, no. 23, Article ID L23611, 5 pages, 2004.

[20] D. Tapete, R. Fanti, R. Cecchi, P. Petrangeli, and N. Casagli, "Satellite radar interferometry for monitoring and earlystage warning of structural instability in archaeological sites," Journal of Geophysics and Engineering, vol. 9, pp. S10-S25, 2012.

[21] The Terrafirma Atlas, "Terrain-motion across Europe. A compendium of results produced by the European space agency GMES service element project Terrafirma 2003-2009," 94 pages, June 2009, http://esamultimedia.esa.int/multimedia/ publications/TerrafirmaAtlas/pageflip.html.

[22] L. Bateson, M. Cuevas, M. Crosetto, F. Cigna, and M. Schijf, D3. 5: PanGeo Production Manual Version 1, 2012, http://www.pangeoproject.eu/sites/default/files/pangeo_other /D3.5_PanGeo_Production_Manual_v1_of_2nd_April_2012. pdf.

[23] National Geoportal, "Extraordinary plan of environmental remote sensing," 2012, http://www.pcn.minambiente.it/GN/ /progetto_pst.php?lan=en.

[24] A. Trigila, C. Cacace, C. Iadanza, S. Del Conte, D. Spizzichino, and S. Cespa, "Cultural heritage, landslide risk and remote sensing in Italy," in The Second World Landslide ForumAbstract Book, F. Catani, C. Margottini, A. Trigila, and C. Iadanza, Eds., p. 603, FAO, Rome, Italy, 2011, ISPRA, WLF22011-0397.

[25] G. Savio, A. Ferretti, F. Novali, S. Musazzi, C. Prati, and F. Rocca, "PSInSAR validation by means of a blind experiment using dihedral reflectors," in Proceedings of FRINGE 2005 Workshop, pp. 1-6, Frascati, Italy, December 2005.

[26] D. Perissin and A. Ferretti, "Urban-target recognition by means of repeated spaceborne SAR images," IEEE Transactions on Geoscience and Remote Sensing, vol. 45, no. 12, pp. 40434058, 2007.

[27] G. Zeni, M. Bonano, F. Casu et al., "Long-term deformation analysis of historical buildings through the advanced
SBAS-DInSAR technique: the case study of the city of Rome, Italy," Journal of Geophysics and Engineering, vol. 8, no. 3, pp. S1-S12, 2011.

[28] D. Tapete and F. Cigna, "Site-specific analysis of deformation patterns on archaeological heritage by satellite radar interferometry," in 20th International Materials Research Congress, Symposium 8 Cultural Heritage and Archaeological Issues in Materials Science, vol. 1374 of MRS Proceedings, Cambridge University Press, 2012.

[29] F. Cigna, S. Bianchini, and N. Casagli, "How to assess landslide activity and intensity with persistent scatterer interferometry (PSI): the PSI-based matrix approach," Landslides. In press.

[30] C. Colesanti and J. Wasowski, "Investigating landslides with space-borne synthetic aperture radar (SAR) interferometry," Engineering Geology, vol. 88, no. 3-4, pp. 173-199, 2006.

[31] National Geoportal, "Progetto persistent scatterers interferometry," 2012, http://www.pcn.minambiente.it/GN/progetto _psi.php?lan=en.

[32] L. Vezzoli, "Stratigraphy of the latera volcanic complex: proposals for a new nomenclature," Periodico di Mineralogia, vol. 56, no. 2-3, pp. 89-110, 1987.

[33] S. Conticelli, L. Francalanci, P. Manetti, and A. Peccerillo, "Evolution of Latera Volcano, Vulsinian district (central Italy): stratigraphical and petrological data," Periodico di Mineralogia, vol. 56, no. 2-3, pp. 175-199, 1987.

[34] P. Canuti, N. Casagli, R. Fanti, A. Iotti, E. Pecchioni, and A. P. Santo, "Rock weathering and failure of the "Tomba della Sirena" in the Etruscan necropolis of Sovana (Italy)," Journal of Cultural Heritage, vol. 5, no. 3, pp. 323-330, 2004.

[35] R. Fanti, G. Gigli, L. Lombardi, D. Tapete, and P. Canuti, "Terrestrial laser scanning for rockfall stability analysis in the cultural heritage site of Pitigliano (Italy)," Landslides. In press.

[36] P. Canuti and R. Fanti, "The instability of Pitigliano's cliff: the role of the anthropic cavities, the geotechnical studies and the monitoring system," in Conservation and Sustainable Development of the Tuff Towns. An Exploration of Pitigliano, World Monuments Fund Publication, Civita di Bagnoregio, Italy, 2007, http://www.wmf.org/sites/default/files/wmf publication/tuff_canuti-en.pdf.

[37] Archivio Galilei 18 ins. 1, Memorie per Pratolino Frana di Bivigliano dell'agosto 1729. 

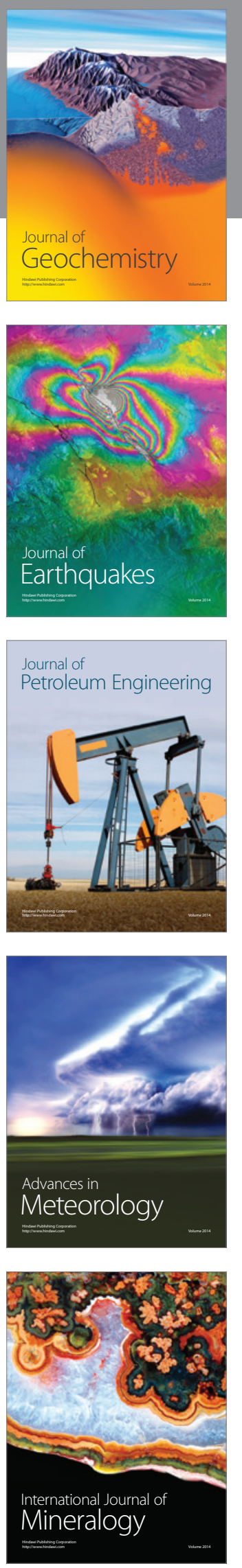
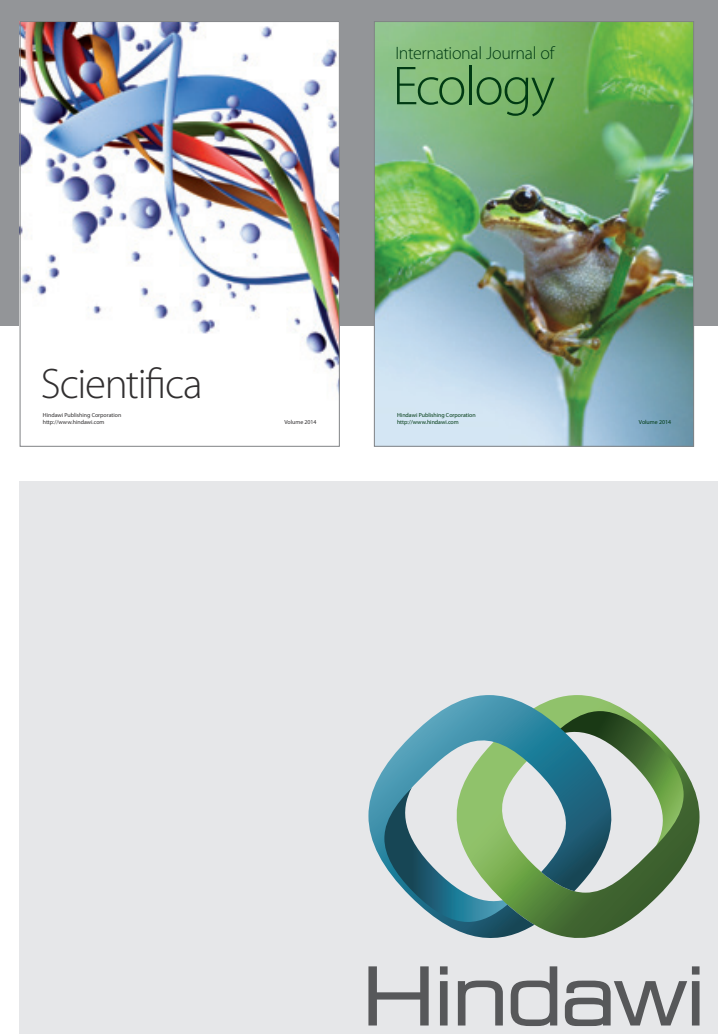

Submit your manuscripts at http://www.hindawi.com
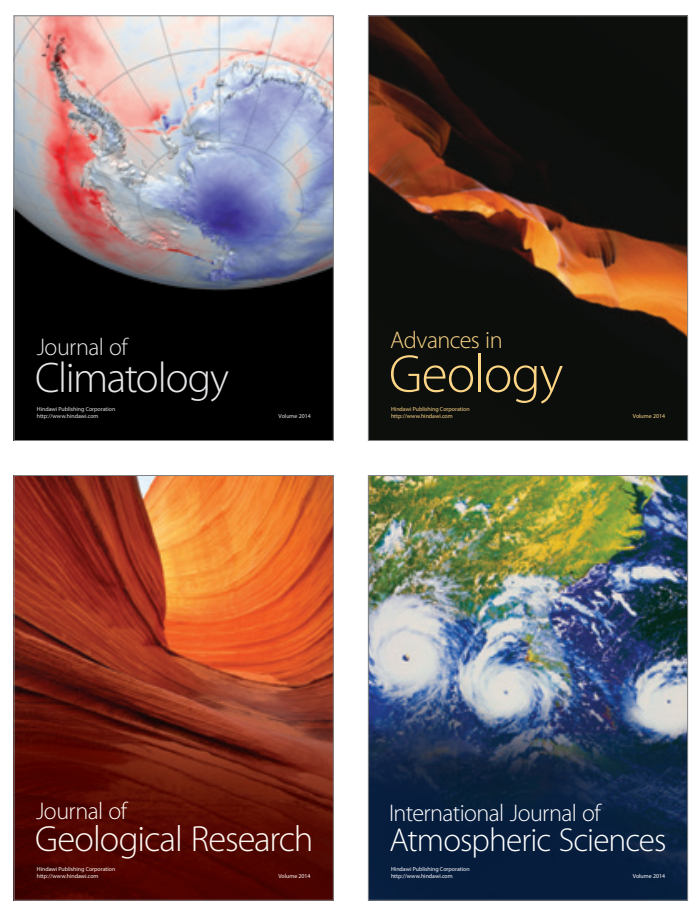
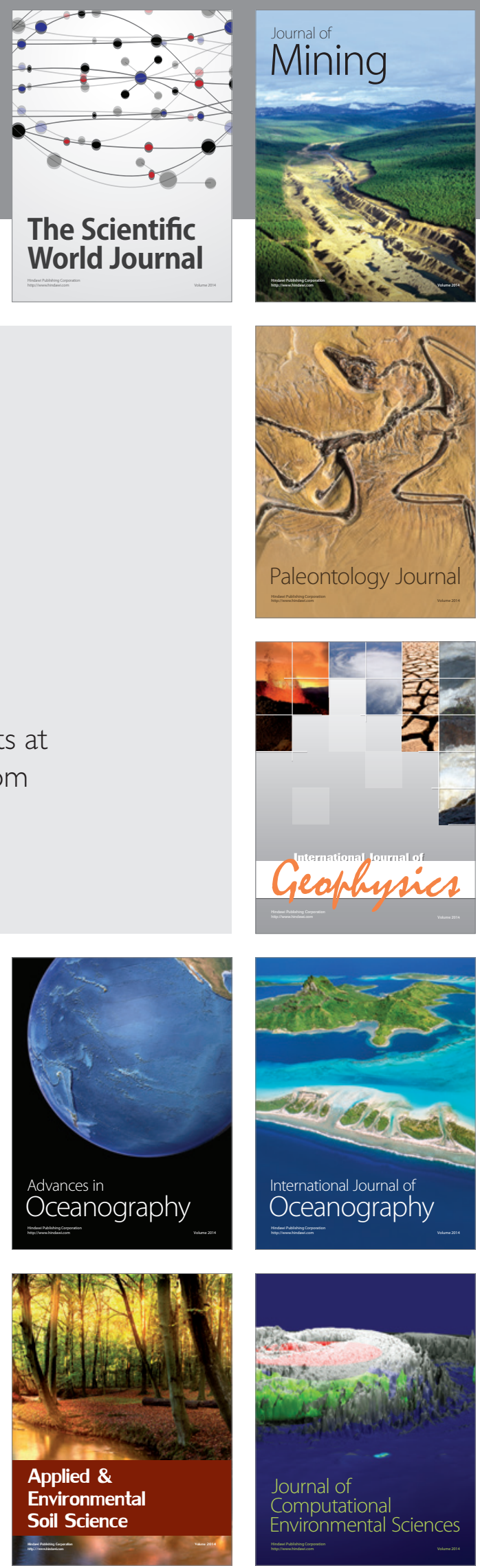